\title{
Characterisation of the chemo-mechanical behaviour of clays polluted by BTEX: a case study of benzene
}

\author{
Hicham KAHLOUCHE ${ }^{{ }^{*}}$ (D) Abderrahim GHERIS ${ }^{2}$ and Mohamed GUENFOUD'
}

\footnotetext{
${ }^{*}$ Correspondence:

kahlouche.hicham@univguelma.dz

${ }^{1}$ Civil Engineering and Hydraulics Laboratory, 8 Mai 1945 University, Guelma, Algeria

Full list of author information is available at the end of the article
}

\begin{abstract}
In chemo-mechanical coupling of clays, chemical phenomena are likely to have a stronger influence on the mechanical behaviour and mechanical actions can modify the chemical behaviour. The understanding of these different phenomena, taking into account the coupled mechanisms, is essential in the context of the problem of the durability of structures and works built on polluted sites. Thus, the laboratory characterisation of the chemo-mechanical behaviour of a clay contaminated by light hydrocarbon pollutant (BTEX: benzene) was carried out. First in the absence of pollutants, i.e., by the presence of water only, then under the influence of the pollutant, all in two stages: with no external stress, then under imposed external stress. This study presents an experimental protocol based on a series of uniaxial consolidation tests, specific oedometric tests and direct shear strength, this tests performed under controlled saturation conditions and in the presence of organic contamination by benzene. All results confirm the influence of pollutants in different concentrations on the mechanical behaviour of the soil. They show a strong increase in compressibility and a significant increase in swelling, the soil becomes more cohesive, low friction and less elastic. Furthermore, the results show that external load forces play a major role in modifying the behaviour of clay.
\end{abstract}

Keywords: Contaminated clay, Organic contaminant, Benzene, Chemo-mechanical coupling, Laboratory tests, Soil rheology

\section{Introduction}

Understanding the chemo-mechanical coupling of clays is of interest to geotechnical engineers and environmental scientists to solve many problems. These issues range from pollution studies to waste control or liquid contaminants produced by an accidental spill of the hydrocarbons are partially dissolved in water to form a mobile phase that can saturate soil pores. Natural clays could be exposed to chemical fluid effects resulting in a modification of their mechanical properties, under natural or artificial causes. The risk of rupture or leakage of a hydrocarbon transport line in natural clay is an important aspect of the study of the stability of this soil to assess the possibility of its future exploitation in the field of construction and others. author(s) and the source, provide a link to the Creative Commons licence, and indicate if changes were made. The images or other third party material in this article are included in the article's Creative Commons licence, unless indicated otherwise in a credit line to the material. If material is not included in the article's Creative Commons licence and your intended use is not permitted by statutory regulation or exceeds the permitted use, you will need to obtain permission directly from the copyright holder. To view a copy of this licence, visit http:// creativecommons.org/licenses/by/4.0/. 
Numerous experimental studies have examined the effect of certain liquids or chemical contaminants on the hydro-mechanical properties of clay by inducing reversible and/or irreversible volume deformation [1-7]. For example, clay samples exposed to saline solutions or organic fluids showed a significant reduction in volume (contraction/expansion) [8]. In addition, permeation of clay with brine has been shown to induce an increase in shear strength [9]. Abdul et al. [10] showed that dehydration cracking of water-wetted smectite and kaolinite in contact under low-stress with insoluble hydrophobic liquids such as benzene and tetrachloroethylene are of particular concern. For clays that are less swellable with non-polar filter solutions such as hydrocarbon contaminated soils, the dielectric constant plays the decisive role in changing permeability. Fernandez and Quigley [11], Delage et al. [12] and Cui et al. [13] carried out permeability tests respectively on a natural Sarnia clay and compacted Jossigny silt (both soils have comparable values of $W_{l}=38$ and $W_{p}=18$ ) with distilled water and some hydrocarbons of different dielectric constants. The authors obtained an increase in hydraulic conductivity k, and also in the intrinsic permeability $\mathrm{K}$ with the decrease in the dielectric constant $\mathrm{D}$. Castellanos et al. [14] carried out swelling, compressibility and permeability tests on dense bentonite with pure water and solutions of different concentrations. The authors reported decreases in compressibility and increases in consolidation rates in samples subjected to flow of high salinity ionic solutions, especially when the applied stresses were low and initial void ratios were high. Conversely, the use of highly compacted clay samples, high vertical stresses or low salinity solutions made the chemical effects negligible.

Many models have been proposed to describe the chemo-mechanical behaviour of soils under saturated and unsaturated conditions [15-17]. In addition, Moyne and Murad [18] developed a macroscale electro-chemo-mechanical constitutive model for expansive clays by rigorously upscaling the micro-structural behaviour. Boukpeti et al. [19] presented a constitutive model of the behaviour of clays subjected to the flow of organic contaminants. Guimaraes et al. [20] developed a fully coupled thermo- hydromechanical model combined with reactive transport in porous media. Detournay and Sarout [21] conducted experiments to determine the critical parameters controlling linear isotropic chemo-elasticity-an extension of Biot porosity-hardness coupled with the effects of the presence and transport of chemical ions in the interstitial fluid. Based on this work, Bunger [22] presented a constitutive model of chemo-poroelasticity and derived solutions for representative problems. Later, Sarout et al. [23] developed a perfectly described elastic model of chemoelasticity, defined in terms of molar volumes of chemical species in the interstitial fluid relative to the solid volume. Hueckel $[24,25]$ developed a chemo-mechanical constitutive model for a single organic contaminant using its concentration in the pore water as the main variable. In this model, Hueckel proposed an exponential relationship between preconsolidation pressure and chemical concentration such that resistance decreases with increasing chemical concentration.

From the above, we can say that the most important factors affecting the chemomechanical coupling of soils exposed or not to pure organic and/or inorganic solutions, concentrated or dilute are: water solubility, dielectric constant, polarity...etc. These factors have a direct influence on hydraulic conductivity, volume change reversible and/or irreversible,, consolidation, and sweling. Therefore, most of the previous studies focused on the characterisation of the chemo-mechanical coupling of reconstituted soils based 
on pure clays. These clays are mainly used in the realization of watertight membranes of the waste repositories toxic, radioactive... etc.

Overall, there are two possible sources of soil pollution: on the one hand, the deposit of waste without sufficient precautions and, on the other hand, the accidental spillage of hydrocarbons due to leaks resulting from the damage or breakage of a hydrocarbon transport pipeline. Geotechnical engineers and environmental scientists are faced with two types of problems. On the one hand, they have to study the permeability of the soil, and its possible evolution with the addition of pollutants, to estimate the risk of migration of these pollutants into groundwater. Secondly, they must study the effect of the pollutants on the mechanical strength of the soil mass of a natural slope, to determine whether its stability is threatened. The durability of the foundations of structures built or to be built on polluted or potentially polluted land must also be studied.

A reference clay was extracted from the region of Constantine, an urban megalopolis located in north-eastern Algeria, which is crossed by an important network of fuel pipelines, as some of these pipelines pass close to urban areas. This paper aims to study the effects of organic chemical liquid on the mechanical behaviour of clay in general. In particular, the effects of a light hydrocarbon (BTEX: Benzene), using usual uniaxial consolidation tests and an specific oedometric tests and a series of shear tests. All tests were carried out under controlled saturation conditions and in the presence of chemical contamination at different concentrations. In addition, the study focuses on the comparison of the behaviour of a water-saturated clay soil with the same soil saturated with benzene. The effect of the interstitial fluid (water and/or benzene) was examined on the permeability of the soil to this fluid, the compressibility measured during oedometric tests and the mechanical strength of the soil measured during direct shear tests.

It is essential to first characterise the clay and organic reference solution to determine its type: physico-mechanical properties, chemical and mineralogical composition. It is also necessary to study the role of the effective stress on clays contaminated by benzene at different concentrations. Variable seepage stresses represent a major interpretation problem. In this work, the chemo-mechanical couplings were addressed by neglecting temperature, not because it is not important, but because in some studies the temperature variation is small [26].

The final objective of this work is to correlate the influence of an organic pollutant "benzene" on the geotechnical characteristics of natural clay by studying several parameters: hydraulic conductivity, chemical consolidation using specific oedometric tests, uniaxial compressibility and mechanical strength determined by direct shear tests. The hydraulic conductivity measurements show that the hydraulic conductivity decreases relatively during the water/benzene transition, which could be explained by the development of macroporosity in the tested clay. The compressibility measured during oedometric tests of the natural clay saturated with benzene is about four times higher than for the samples saturated with water. Finally, consolidated box shear test established that a significant decrease in the shear strength of the samples occurred when the soils were saturated with benzene. 


\section{Study area}

The study area is located in the wilaya of Constantine, in the north-east of Algeria. This area contains a complex topography with a great variability of lithological formation. This region is strongly affected by the risk of landslides due to its geomorphological, geological, climatic and seismotectonic conditions [27]. The geographical position of the sampling site located at $36^{\circ} 23^{\prime} 00^{\prime \prime}$ north of the equator, and $6^{\circ} 75^{\prime} 00^{\prime \prime}$ east of the Greenwich line, according to UTM (Universal Transverse Mercator) coordinates is $\mathrm{X}=297,787.52 \mathrm{E}$ and $\mathrm{Y}=4,011,806.64 \mathrm{~N}$, with an altitude of $\mathrm{Z}=650 \mathrm{~m}$ above sea level. Figure 1 shows the location of the test area.

\section{Materials and methods}

The sampling operation was carried out along the route of the fuel pipeline crossing the study area (Fig. 1). The study samples were taken near the surface $(-3 \mathrm{~m}$ deep) from the cores of the boreholes made. The boreholes identified a homogeneous layer of light brown clay overlying grey-brown to grey-black shale clays.

In the first stage, they were analysed for identification according to the usual geotechnical tests (Fig. 2). The soil was characterized using the current ASTM tests for soils [28]. Specific gravity (ASTM D854), sieve analyses (ASTM C136), hydrometer analyses (ASTM D422), Atterberg limits (ASTM D4318) and proctor compaction (ASTM D698) tests were performed. The mechanical properties of the clay, which were internal friction angle and cohesion, were determined using a rectilinear shear box (ASTM D3080). Volume changes due to swelling were identifed by an automatic computer-controlled oedometer (ASTM D2435). free-swelling tests were carried out according to the standard (ASTM D4546). The soil properties are also summarized in Table 1.

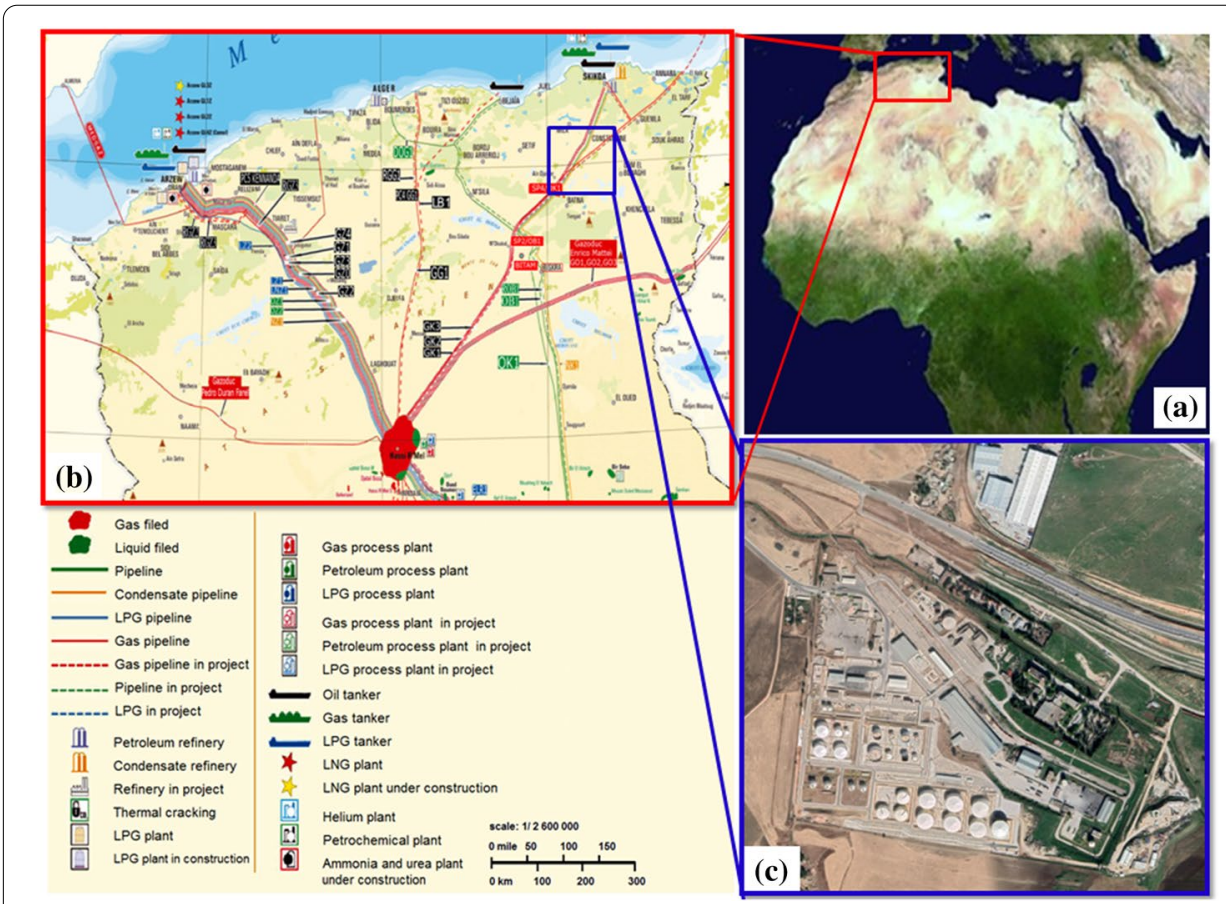

Fig. 1 Soil sampling area: a Geographical location of Constantine region; b Pipeline transportation of crude oil and refined petroleum; c Refining station near the study area 


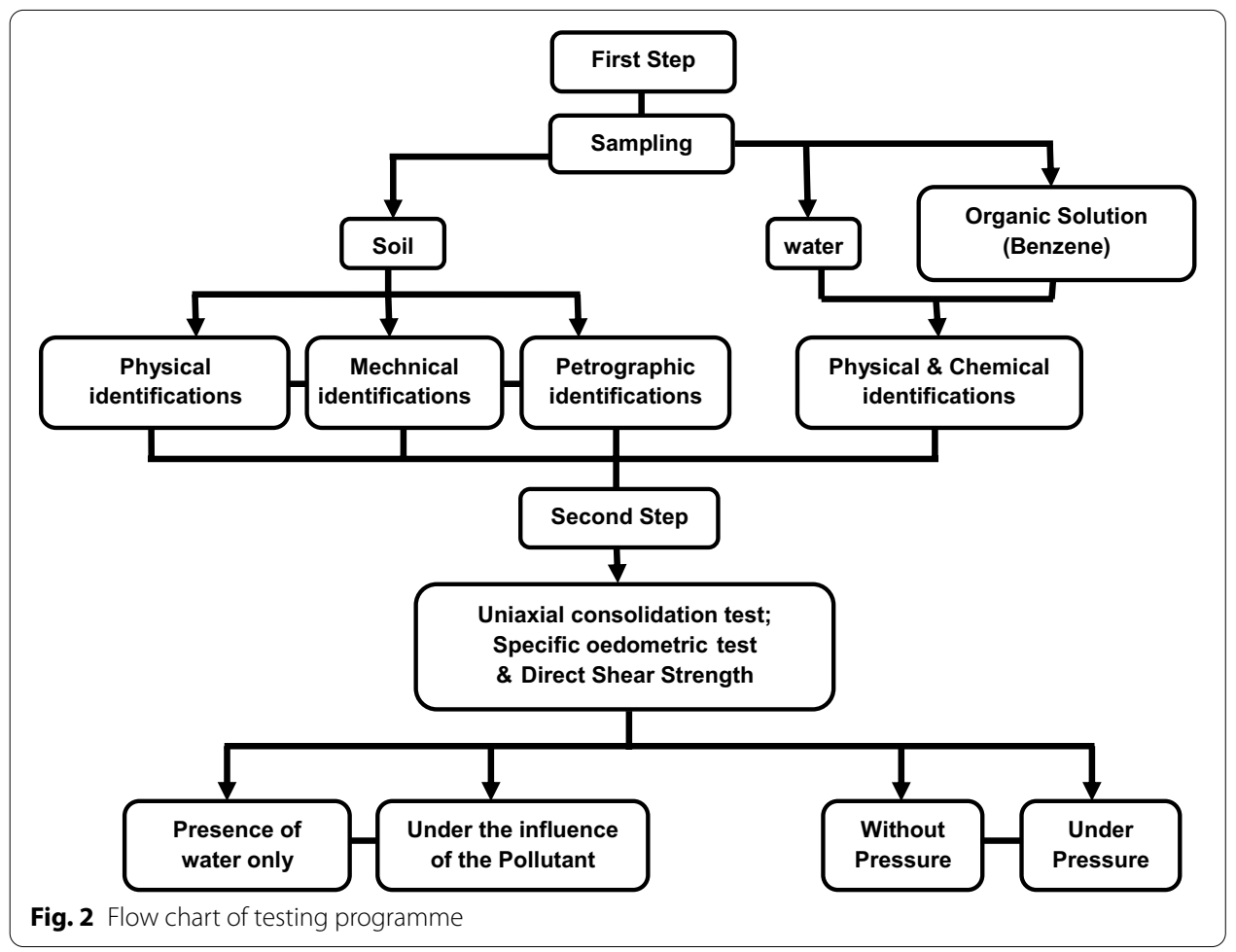

Table 1 Basic parameters of uncontaminated soil

\begin{tabular}{|c|c|c|c|c|c|c|c|}
\hline \multirow[t]{2}{*}{ Parameters } & & \multicolumn{5}{|c|}{ Sampling sites } & \multirow[t]{2}{*}{ Mean values } \\
\hline & & $\mathrm{S}_{1}$ & $\mathrm{~S}_{2}$ & $\mathrm{~S}_{3}$ & $\mathrm{~S}_{4}$ & $\mathrm{~S}_{5}$ & \\
\hline Dry density & $\rho d\left(\mathrm{~g} / \mathrm{cm}^{3}\right)$ & 1.774 & 1.781 & 1.726 & 1.738 & 1.736 & 1.751 \\
\hline Wet density & $\rho h\left(\mathrm{~g} / \mathrm{cm}^{3}\right)$ & 2.049 & 2.062 & 2.014 & 2.030 & 2.036 & 2.038 \\
\hline Natural water content & Wn (\%) & 15.50 & 15.80 & 16.70 & 16.80 & 17.30 & 16.42 \\
\hline Liquidity limit & WI (\%) & 52 & 56 & 53 & 53 & 56 & 54 \\
\hline Plasticity index & $\mathbb{I P}(\%)$ & 48 & 44 & 47 & 47 & 44 & 46 \\
\hline Coefficient of consistence & IC & 1.26 & 1.34 & 1.34 & 1.36 & 1.17 & 1.29 \\
\hline Porosity & $\eta$ & 33.60 & 33.30 & 35.40 & 34.90 & 35.00 & 34.44 \\
\hline Void ratio & e & 0.505 & 0.499 & 0.547 & 0.536 & 0.538 & 0.525 \\
\hline$\%$ passing through $0.2-\mathrm{mm}$ sieve & - & 94.09 & 94.38 & 93.68 & 93.76 & 93.70 & 93.92 \\
\hline$\%$ passing through $75-\mu \mathrm{m}$ sieve & - & 78.22 & 78.49 & 77.82 & 77.91 & 77.68 & 78.02 \\
\hline Proportion of clay $\%<2 \mu \mathrm{m}$ (F2) & - & 63.24 & 63.44 & 63.89 & 62.79 & 62.65 & 63.20 \\
\hline Coefficient of permeability $(\mathrm{m} / \mathrm{s})$ & $\mathrm{K}(\mathrm{m} / \mathrm{s}) \times 10^{-8}$ & 9.92 & 9.92 & 9.92 & 9.92 & 9.92 & 9.92 \\
\hline \multirow[t]{2}{*}{ Cohesion } & $\mathrm{C}_{\mathrm{CD}}(\mathrm{kPa})$ & 35.85 & 35.46 & 34.14 & 34.33 & 35.22 & 35.00 \\
\hline & $\mathrm{C}_{\mathrm{Uu}}(\mathrm{kPa})$ & 53.32 & 54.12 & 52.88 & 53.54 & 53.24 & 53.42 \\
\hline Internal friction angle & $\varphi_{\mathrm{CD}}\left(^{\circ}\right)$ & 17.44 & 16.61 & 16.33 & 15.70 & 16.13 & 16.44 \\
\hline Pre-consolidation stress & $\sigma_{c}^{\prime}(\mathrm{kPa})$ & 90.5 & 91.13 & 90.22 & 91.20 & 90.45 & 90.70 \\
\hline Compressibility index & $\mathrm{Cc}$ & 0.20 & 0.21 & 0.19 & 0.21 & 0.19 & 0.20 \\
\hline Swelling index & $\mathrm{Cs}$ & 0.04 & 0.05 & 0.03 & 0.05 & 0.03 & 0.04 \\
\hline Swelling potential & $G \%$ & 4.97 & 5.10 & 5.30 & 5.48 & 5.56 & 5.28 \\
\hline Swelling pressure & $\mathrm{Ps}(\mathrm{kPa})$ & 14.50 & 15.50 & 18.00 & 21.50 & 19.50 & 17.80 \\
\hline
\end{tabular}


In the second part of the experiment, the mineralogical composition was obtained by $\mathrm{X}$-ray diffraction $(\mathrm{XRD})$ on fractions $<2 \mu \mathrm{m}$. The difractometer used $\mathrm{Cu} \mathrm{K} \alpha$ radiation $(\lambda \mathrm{Cu}=0.154056 \mathrm{~nm})$, a nominal tube voltage of $40 \mathrm{kV}$ and a nominal current of $30 \mathrm{~mA}$, and data was collected for $2 \theta$ values of $7^{\circ}-90^{\circ}$. The X'Pert High-Score Plus V3.0 (PANalytical ${ }^{\circledR}$ ) software program was used to identify the mineral phases in each X-ray powder spectrum by comparing experimental peaks with PDF2 reference models. Microscope imaging was performed using a stereomicroscope, while the morphology of the dried clay surface was observed with a scanning electron microscope (SEM) equipped with an SE1 probe for surface microanalyses. Type I secondary electrons (SE1) emit at a high angle in the immediate vicinity of the point of impact and therefore transport high-resolution and sensitive (topographic) information to the surface of the sample. The X-ray fluorescence (XRF) analysis of the clay sample was performed using a wavelength dispersive XRF spectrometer with a power of $1 \mathrm{~kW}$. The samples for chemical and mineralogical analysis (XRF and XRD) were first crushed into pieces using a mortar and then dried in an oven for $24 \mathrm{~h}$ at $105^{\circ} \mathrm{C}$. Then the pieces were ground and the powder obtained was sieved through a $50 \mu \mathrm{m}$ diameter sieve. The analysis was carried out at the Applied Research Unit in Iron and Steel Metallurgy of the Industrial Technologies Research Centre (ARUSM-ITRC).

In the third part of the experiment, chemical coupling tests were carried out with an organic liquid (light hydrocarbon: benzene) at different concentrations. This stage presents an experimental protocol based on a series of usual uniaxial consolidation tests and a specific oedometric tests, carried out under controlled saturation conditions and in the presence of chemical contaminants. The tests were carried out first in the absence of chemical liquids, i.e., in the presence of water only, and then under the influence of the pollutant, under different pressures. In addition, a series of shear tests were carried out using a straight shear box under the same circumstances.

Finally, to determine the different concentrations of the benzene leachate mixture in the soil matrix, the percolate (leachate) was recovered in chemically inert tubes to obtain a sufficient quantity at each sampling. These leachates were then analysed by chromatographic analysis (HPLC) was obtained using a technique called: CPG-FID (gas chromatography coupled to a flame ionisation detector, Perkin Elmer Clarus 580) with an HS sampler (headspace, Perkin Elmer Turbo-matrix 40 with a transfer line). This method allows the separation of compounds that can be vaporised by heating (without decomposition). The separation is done in a column either by partitioning or absorption. It allows: microanalysis, separation of complex mixtures, easy qualitative and quantitative analysis, analyses in many fields of applications. This analysis was carried out in the toxicology laboratory of the CHU of Annaba.

\section{Experimental studies}

The experimental study consists of characterising the behaviour of soils contaminated by an organic solution (benzene) to understand their effect on improving the mechanical performance of soils. To this end, a series of tests were carried out in the laboratory, focusing on shear and uniaxial compression. Samples were taken from the clay cores extracted from the study site, and their faces were erected to obtain flat surfaces parallel to each other and perpendicular to the sample. After being cut, the samples were 
subjected to the usual uniaxial consolidation tests, specific oedometric tests and direct shear strength tests according to the test protocol. These tests were carried out first in the absence of pollutants (water only) and then under the influence of the pollutant at different concentrations.

\section{Uniaxial consolidation test}

For the purpose of determining the compressive strength, the uniaxial compressive experiment were carried out in accordance with standard (ASTM D2435). The soil is placed in a Proctor mould and allowed to consolidate under a low load (about $10 \mathrm{kPa}$ ). The sample is taken and cut to the dimensions of the oedometer cell ring (diameter $50 \mathrm{~mm}$, height $20 \mathrm{~mm}$ ). A charge-discharge-recharge cycle is carried out at $20 \mathrm{kPa}$ to mitigate the effects of sample preparation. The experiment is carried out in 24-h charge stages, followed by a 24-h discharge stage.

\section{Specific oedometric test}

A modified oedometric cell for the permeability test is used to simulate the seepage of pollutants through the clay layer. The cell is machined from a stainless material, with a diameter of $50 \mathrm{~mm}$ and a height of $20 \mathrm{~mm}$. Porous bronze discs, surmounted by a Teflon ring, are placed at the top and bottom of the cell to allow the passage of liquid and air through the sample, and are protected by paper filters to prevent the clay from clogging the pores. This cell is equipped at the top with a piston to control the axial mechanical stress imposed on the sample. The displacements of the piston are read by means of a comparator to measure the vertical deformation of the sample. The vertical displacement is monitored by an electronic comparator connected to a data acquisition system consisting of a multiplexer by which several comparators are connected to a computer.

Figure 3 shows a system consisting of a tank filled with de-aerated demineralised water or a chemical solution. The modified oedometer cell and syringe are connected to the compressed air network and equipped with pressure inlet and outlet valves. The distilled water or chemical solution is injected under different pressures according to the test protocol into the test specimens from bottom to top. In this way, the injection pressure of the solution is controlled separately from the mechanical stress applied to the clay specimen. Compaction was carried out in stages. Seepage was imposed with a constant injection pressure of $355 \mathrm{kPa}$ on the underside of the clay slab, while the underside was subjected to various mechanical stresses ( 0 to $160 \mathrm{kPa})$. The measurement of the volume of solution entering the clay slab was carried out regularly, as well as the measurement of the axial deformation of the clay during solution saturation and then throughout the tests by reading the comparators. The percolate (leachate) was recovered in chemically inert tubes to obtain a sufficient quantity at each sampling. These leachates were then analysed by HPLC to determine the concentration in the soil matrix.

The data retrieved with the comparators allow to calculate the infiltrated volumes as a function of time, then to calculate the hydraulic gradient and the hydraulic conductivity at saturation based on Darcy's law:

$$
Q=K * i S
$$




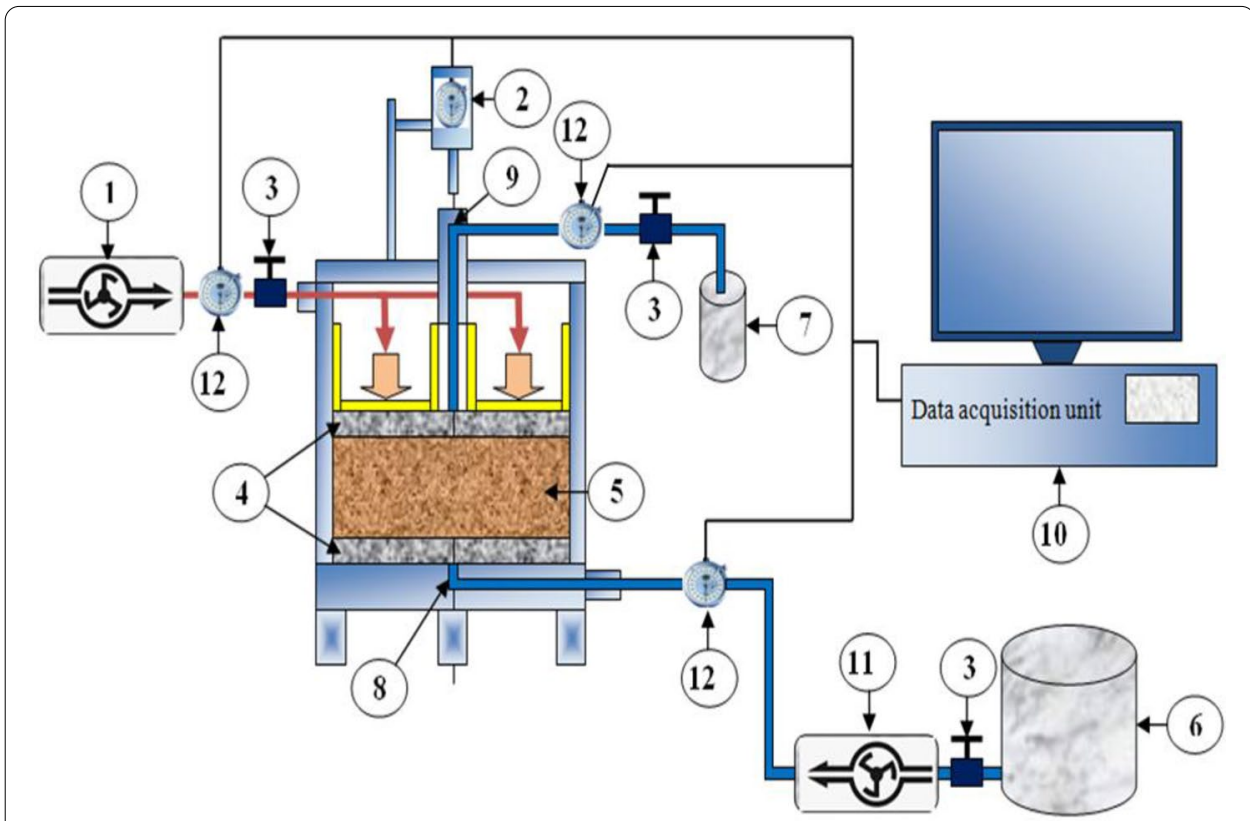

Fig. 3 Schematic of Specific odometric cell: 1—Pneumatic pump; 2-electronic displacement LVDT sensor; 3-Control valve; 4-porous disc; 5-sample; 6-tank of solution; 7-Recovery tank (leachate); 8-Drainage pore water pressure or back pressure; 9-Top drainage and back pressure; 10 - Steering and Data Acquisition Unit; 11—Hydraulic pump; 12—Pressure sensor

where, $Q$ is the flow rate $\left(\mathrm{m}^{3} / \mathrm{s}\right), K$ is the hydraulic conductivity $(\mathrm{m} / \mathrm{s}), i$ is the hydraulic gradient and $S$ is the cell cross section $\left(\mathrm{m}^{2}\right)$. The hydraulic gradient $i$ is obtained formula follows:

$$
i=\frac{h}{e}
$$

where, $h$ is the height of water ( $35.5 \mathrm{~m}$ which corresponds to $355 \mathrm{kPa}$ ), and $e$ is the final thickness of the clay cake in $\mathrm{m}$.

\section{Direct shear strength test}

Direct shear tests to determine the shear strength of soil contaminated with organic solution were carried out in accordance with the standard (ASTM D3080). This strength is characterised by the cohesion and the internal friction angle. For this purpose, several samples were cut according to the shape of the shear box mold. The internal dimensions of the shear box used in our study were a length of $60 \mathrm{~mm}$, a width of $60 \mathrm{~mm}$ and a height of $20 \mathrm{~mm}$. The tests were carried out in consolidated and drained modes (the consolidation stress was applied in such a way as to have a maximum dry density $\left(\gamma_{d \max }=1.75\right)$ at a speed of $0.002 \mathrm{~mm} / \mathrm{min}$.

The direct shear experiment for each sample under the same experimental conditions was carried out 2 to 3 times. The normal stress, which is $100 \mathrm{kPa}, 200 \mathrm{kPa}$ and $300 \mathrm{kPa}$, was exerted for each set of samples. For each specimen, at the beginning of the experiment, the normal stress was exerted on the specimen. A horizontal thrust force is exerted when the specimen is under the conditions of a certain normal stress and in the 
steady state. During the experiment, the final displacement is recorded when there is no displacement for each calibration load. The experiment is not stopped until the displacement shows a continuous increase under a certain shear stress. When the experiment is completed, the normal stress is first relieved, and then the horizontal stress is unloaded. When all experiments are completed, the results are processed and analysed on the basis of the stress and displacement curve.

\section{Results and discussion}

\section{Characterization of the soil study and organic chemical contaminant}

Unaltered samples taken from the site's clay layer were subjected to physical and mechanical identification tests. Table 1 summarises the results.

The properties that were measured are as follows: granulometry, characterised by the percentage of grains with size $<2 \mu \mathrm{m},(F 2 \approx 63.2)$, where, $\mathrm{F} 2$ is the proportion of clay \% $<2 \mu \mathrm{m}$. The void ratios $\left(e_{0}\right)$ and water contents $\left(W_{0}\right)$ indicate a stiff clay [29], saturated but below their plasticity limit. Coefficient of permeability is $K=9.92 \times 10^{-8} \mathrm{~m} / \mathrm{s}$. The plasticity index is deduced from the Atterberg limits values. Placing these values in the Casagrande diagram used for the classification of fine soils, it can be seen that these clays are moderately moist, plastic, of firm to medium-hard consistency $\left(1.17<I_{C}<1.36\right)$, with low to medium compressibility $\left(C_{c} \approx 0.18\right.$ to 0.23$)$. The drained cohesion varies from $\left(C_{C D} \approx 34.14\right.$ to $\left.35.85 \mathrm{kPa}\right)$ for an internal friction angle of $\left(\phi_{C D} \approx 15.70^{\circ}\right.$ à $\left.17.44^{\circ}\right)$. With regard to the swelling of these soils, they can be classified as moderately swollen. The Cs coefficients (determined by conventional oedometer tests) vary between (0.03 and 0.05 ). The swelling potential $G$ varies from (4.97 to 5.56\%). The characteristics obtained from the tests reveal a very plastic clay soil (Atterberg limit) and a high clay activity (Ac $>0.72)$, where $(A c=I p / F 2)$. The soil is neither very dense nor very moist.

The characteristics of demineralized water and chemical liquid (benzene) are also summarized in Table 2.

\section{Petrographic identification of clay minerals}

\section{$X$-ray fluorescence}

The results indicate that the predominant constituents are silica, calcium and aluminium. Table 3 shows the predominantly silico-aluminous nature of clays samples with moderate iron oxide contents.

Table 2 Physical and chemical properties of test permeant at $-20^{\circ} \mathrm{C}$

\begin{tabular}{|c|c|c|c|c|c|c|c|}
\hline Liquid & $\begin{array}{l}\text { Structural } \\
\text { formula }\end{array}$ & $\begin{array}{l}\text { Formula } \\
\text { weight (g/ } \\
\text { mol) }\end{array}$ & $\begin{array}{l}\text { Water } \\
\text { solubility } \\
\text { (g/L) }\end{array}$ & $\begin{array}{l}\text { Density (g/ } \\
\text { cc) }\end{array}$ & $\begin{array}{l}\text { Viscosity } \\
\text { (mPa. s) }\end{array}$ & $\begin{array}{l}\text { Dipole } \\
\text { moment } \\
\text { (D) }\end{array}$ & $\begin{array}{l}\text { Dielectric } \\
\text { constant } \\
(\epsilon)\end{array}$ \\
\hline $\begin{array}{l}\text { Water } \\
\left(\mathrm{H}_{2} \mathrm{O}\right)\end{array}$ & & 18.00 & $\infty$ & $\begin{array}{c}0.9982 \\
(0.9982)\end{array}$ & $\begin{array}{c}1.0038 \\
(1.0038)\end{array}$ & 1.85 & 80.1 \\
\hline $\begin{array}{l}\text { Ben- } \\
\text { zene }\end{array}$ & & 78.11 & 0.7 & $\begin{array}{c}0.8780 \\
(0.8778)\end{array}$ & $0.647(0.7243)$ & 0.0 & 2.28 \\
\hline
\end{tabular}


Table 3 The chemical composition elemental of the clay sample studied

\begin{tabular}{|c|c|c|c|c|c|c|}
\hline \multirow{2}{*}{$\begin{array}{l}\text { Mass \% of } \\
\text { elements }\end{array}$} & \multicolumn{5}{|c|}{ Samples } & \multirow[t]{2}{*}{ Means values } \\
\hline & $\mathrm{S}_{1}$ & $\mathrm{~S}_{2}$ & $S_{3}$ & $\mathrm{~S}_{4}$ & $S_{5}$ & \\
\hline $\mathrm{SiO}_{2}$ & 53.35 & 54.15 & 54.28 & 55.43 & 55.63 & 54.57 \\
\hline $\mathrm{Al}_{2} \mathrm{O}_{3}$ & 18.36 & 18.51 & 18.26 & 19.15 & 18.82 & 18.62 \\
\hline $\mathrm{CaO}$ & 6.87 & 5.72 & 6.18 & 6.58 & 6.64 & 6.40 \\
\hline $\mathrm{Fe}_{2} \mathrm{O}_{3}$ & 5.38 & 5.54 & 5.40 & 5.85 & 5.74 & 5.58 \\
\hline $\mathrm{MgO}$ & 2.13 & 2.34 & 2.15 & 2.18 & 2.20 & 2.20 \\
\hline $\mathrm{SO}_{3}$ & 1.89 & 2.34 & 1.81 & 1.58 & 2.02 & 1.93 \\
\hline $\mathrm{MO}$ & 0.94 & 1.48 & 1.28 & 1.55 & 1.17 & 1.28 \\
\hline $\mathrm{K}_{2} \mathrm{O}$ & 1.35 & 1.38 & 1.25 & 1.4 & 1.42 & 1.36 \\
\hline $\mathrm{TiO}_{2}$ & 0.74 & 0.69 & 0.82 & 0.94 & 0.95 & 0.83 \\
\hline $\mathrm{PaF}$ & 7.94 & 6.79 & 7.52 & 4.27 & 4.41 & 6.19 \\
\hline Total & 98.95 & 98.94 & 98.95 & 98.93 & 99.00 & 98.95 \\
\hline
\end{tabular}

The percentage of silica and aluminium is very important, indicating the presence of kaolinite $\left(\mathrm{Al}_{2} \mathrm{Si}_{2} \mathrm{O}_{5}(\mathrm{OH})_{4}\right)$. As for calcium which is relatively high, so this material is therefore rich in calcite $\left(\mathrm{CaCO}_{3}\right)$. The alumina/silica ratio, indicates the permeability of the material to moisture, the higher the ratio, the greater the permeability. In this case, this ratio is small $\mathrm{Al}_{2} \mathrm{O}_{3} / \mathrm{SiO}_{2} \approx 0.34$. This low value is in agreement with the low percentage of humidity (6.19\%) estimated by the loss on fire. The molar ratio $\mathrm{SiO}_{2} / \mathrm{Al}_{2} \mathrm{O} 3=2.93$ (maximum substitution of $\mathrm{Si} 4+$ by $\mathrm{Al} 3+$ ) is higher than the classical bentonite value of 2.7. This difference indicates the presence of free Quartz in the clay fraction in large proportion [30]. The overall composition of other oxides $\left(\mathrm{Fe}_{2} \mathrm{O}_{3}, \mathrm{MgO}, \mathrm{SO}_{3}, \mathrm{~K}_{2} \mathrm{O}, \mathrm{TiO}_{2}\right.$ et $\mathrm{MO}$ ) reached a percentage of $13.18 \%$, which shows that the clay studied was not pure. It is a mixture of silicate and carbonate minerals in very high proportion.

\section{$X$-ray diffraction}

The diffractogram was obtained from an altered sample placed directly as a powder in a conventional sample holder [31]. Figure 4 shows the XRD spectrum of the raw clay.

Spectral analysis indicates that the sample was composed of $65 \%$ Quartz $\left(\mathrm{SiO}_{2}\right), \quad 12 \%$ Calcite $\mathrm{C}_{\mathrm{a}}\left(\mathrm{CO}_{3}\right), \quad 15 \%$ Kaolinite $\left(\left(\mathrm{Al}_{2} \mathrm{Si}_{2} \mathrm{O}_{5}(\mathrm{OH})_{4}\right), \quad 5 \%\right.$ Dickite $\left(\mathrm{Al}_{2} \mathrm{Si}_{2} \mathrm{O}_{5}(\mathrm{OH})_{4} \mathrm{HCONH}_{2}\right)$ and $4 \%$ Sepiolite $\left(\mathrm{Mg}_{4} \mathrm{Si}_{6} \mathrm{O}_{15}(\mathrm{OH})_{2} 6 \mathrm{H}_{2} \mathrm{O}\right)$, which is a subgroup of kaolinite. The results reveal the presence of two intense peaks. The sample is essentially composed of quartz, kaolinite and dickite, as well as other phases that should not be excluded. This implies that our clay is heterogeneous. The intensities of this diffractogram show that quartz is the dominant phase, in fact the peaks at 21.01, 26.75 and $60.10(2 \theta)$ are characteristic of this material, as well as kaolinite, whose presence in the sample is determined by the main peaks at 12.67 and $20.3(2 \theta)$. The peak at $12.67(2 \theta)$ corresponding to the main line $\mathrm{d}(001)(7.13 \AA)$ is of lesser intensity compared to quartz, the other harmonics of the spectrum are also of the same amplitude, suggesting that the clay studied is a kaolinite. These results are in perfect agreement with the SEM observations presented in the following sous-section. The clay fraction studied is composed of quartz, calcite and sepiolite as major impurities in the sample, which confirms the results of the X-ray fluorescence, which showed high proportions of quartz and calcite. 


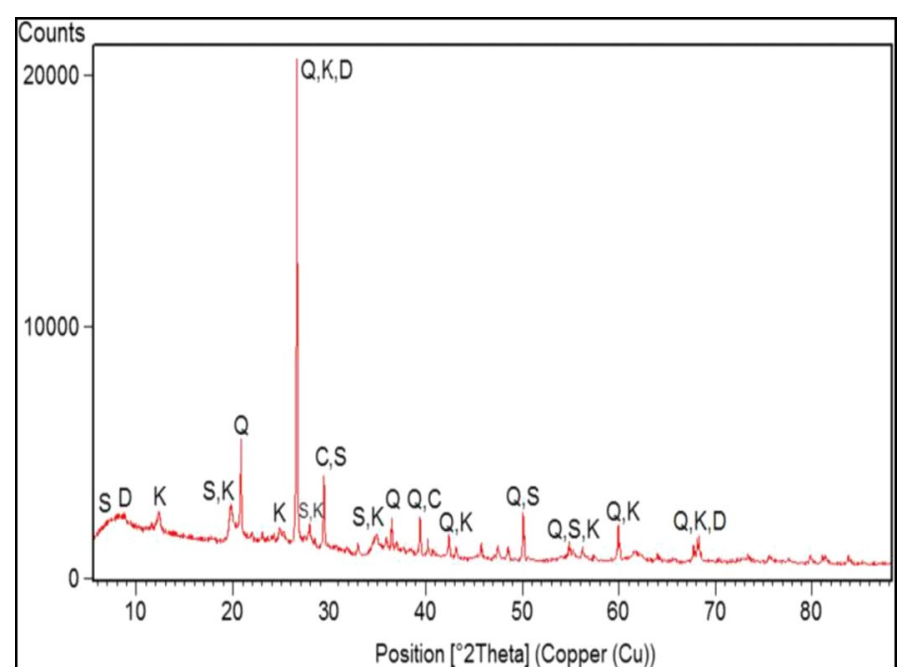

Fig. 4 X-ray difractogram of the studied raw clay, K: kaolinite; D: dickite; Q: quartz; C: calcite; S: sepiolite

\section{Scanning electron microscope (SEM)}

Scanning microscopy allows the observation of the texture of the sample and the characterisation of its mineralogical assemblages. Figure 5 shows the SEM images of the clay sample at different magnifications. Figure $5 \mathrm{a}, \mathrm{b}$ is consistent with that obtained in XRD, clearly showing the presence of carbonates (calcite) and Quartz in the sample. The carbonates (calcite) are in the form of clearly visible aggregates and the Quartz in the form of small grains [32]. The clay particles are shown as fine aggregates and rod-shaped platelets with irregular contours Fig. 5c, d. This is a morphology encountered in both Kaolinites and poorly crystallised Illites, as observed by Konan et al. [33]. The micrographic images show a porous aspect of the material studied, which will facilitate the fixation of metal oxides on the support during the preparation of catalysts. Consequently, the contaminant penetrates and is well distributed on the clay.

\section{Characterisation of clay behaviour saturated with water and benzene at different concentrations}

\section{During uniaxial consolidation test}

Uniaxial consolidation tests were carried out on samples of natural clay saturated with distilled water and benzene at different concentrations. The curves obtained are shown in Fig. 6 and reveal the experimental dispersion of uniaxial compressibility due to changes in the initial benzene content of the water at different concentrations. The compression curves are not straight lines but convex. Figure 6 shows a superposition of the oedometer curves, showing the variation of the void index with respect to the external loading according to various concentrations of benzene (from 0 to 100\%).

The void index $e_{0}$ clearly distinguishes between water-saturated and benzene saturated clays. The results show a strong increase in the void index $\left(e_{0}=0.93\right)$ in clay saturated with water only, and in clay saturated with benzene at different concentrations $e_{0}$ become $1.56 ; 1.73 ; 1.83 ; 1.97 ; 2.00$ respectively with $\mathrm{c}=20 ; 40 ; 60 ; 80$ and $100 \%$. This result places 

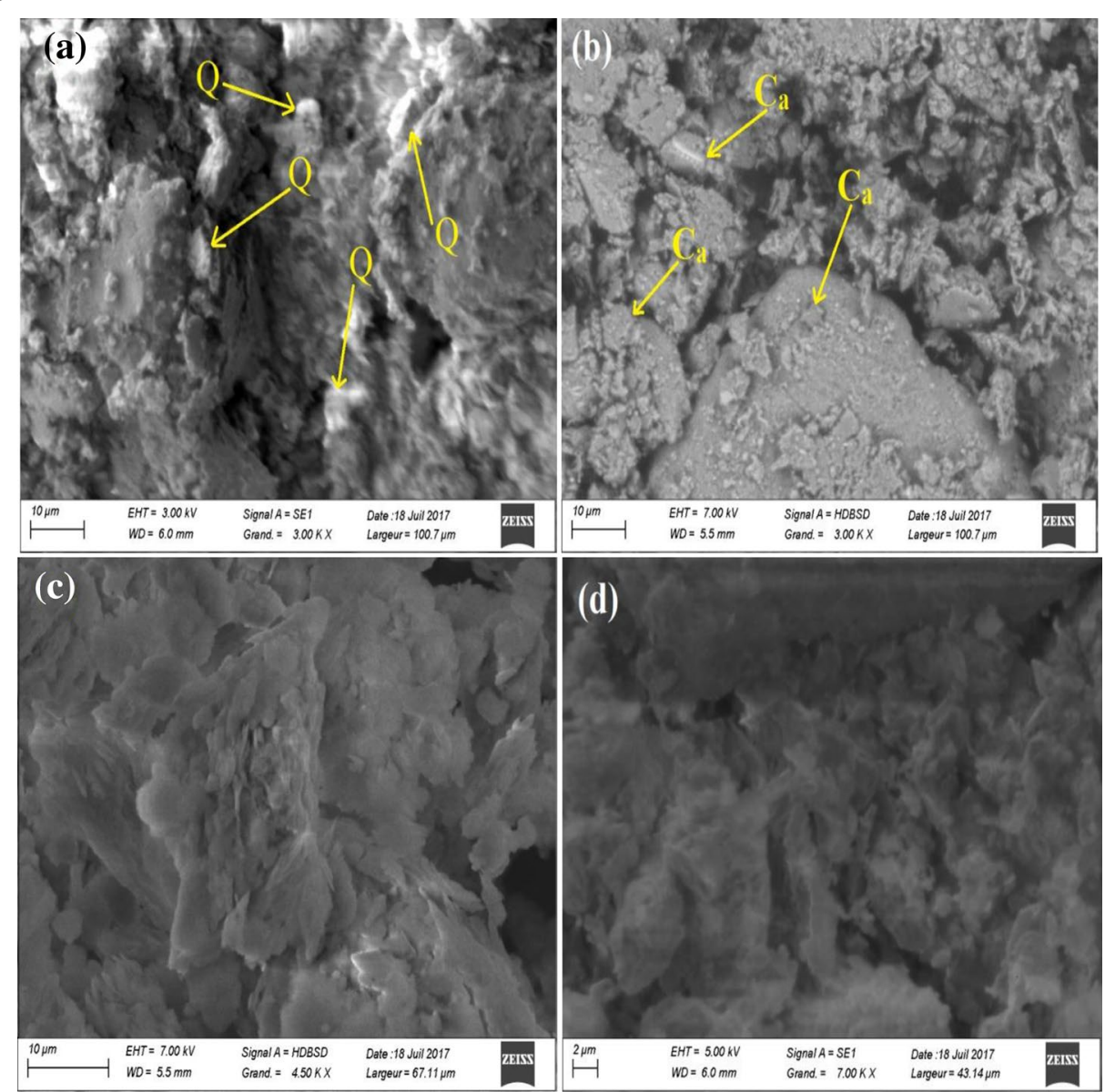

Fig. 5 Scanning electron microscope observations of the clay studied

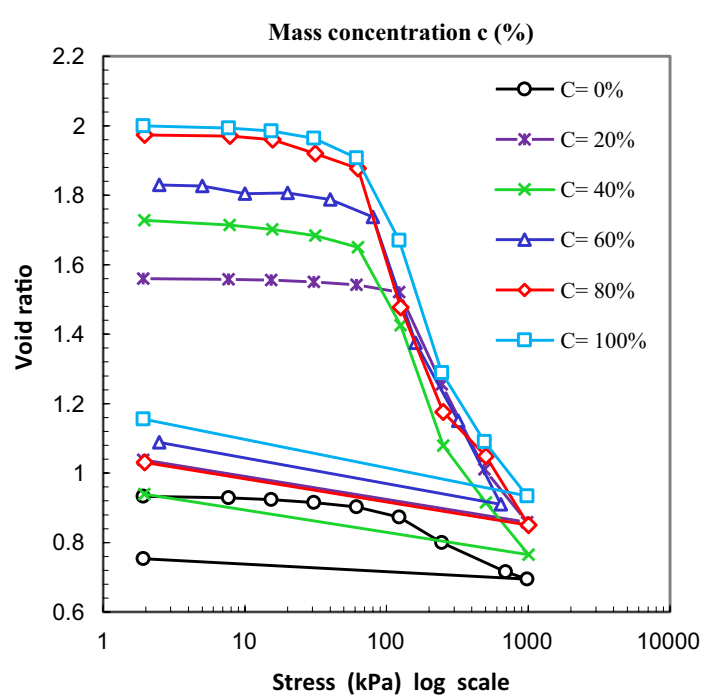

Fig.6 Experimental data of Odometric tests of clay saturated with water only and Benzene at various concentrations 
the intrinsic compression curve of the water saturated clay well below that of the benzene saturated clay. In addition, the intrinsic compression curves of the water saturated clay relative to that of the benzene saturated clay do not show discharge-recharging hysteresis loops (Fig. 6). These loops result in elastic limits lower than the pre-consolidation stress: $\sigma_{v 0}^{\prime}<\sigma_{c}^{\prime}$. The initial effective stress was been estimated by the Casagrande technique as $\sigma_{\mathrm{v} 0}^{\prime}=38 \mathrm{KPa}$.

Figure $7 \mathrm{a}-\mathrm{f}$ shows the measured vertical stress-void ratio relationship for the case of natural clay samples saturated with distilled water and the organic solution at different concentrations.

The slope Cc increases with increasing concentration of benzene. At low concentrations $(c=20 \% \& c=40 \%)$, compressibility is more than with distilled water, while a

(a) Mass concentration $\mathrm{c}=0 \%$ (water only)

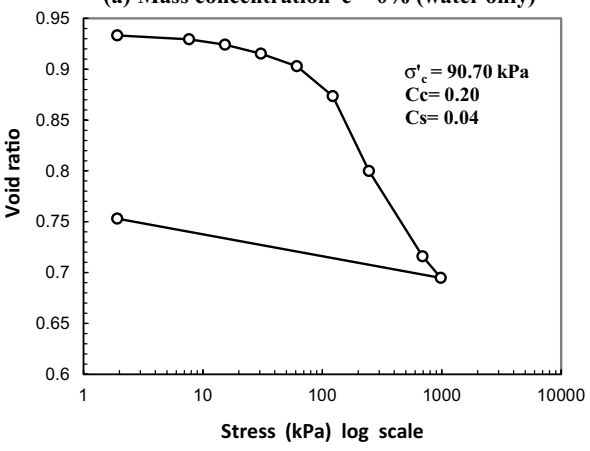

(c) Mass concentration $c=\mathbf{4 0} \%$

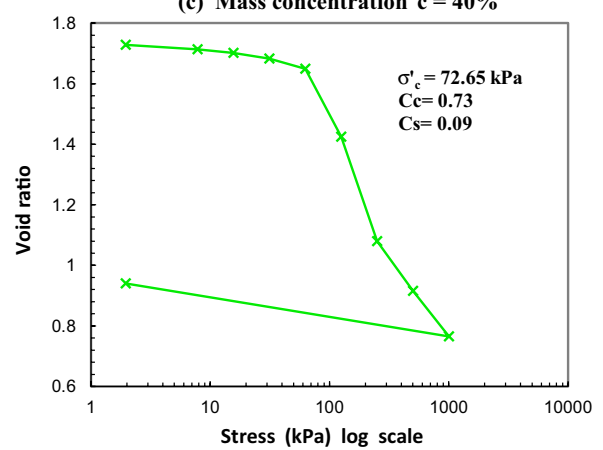

(e) Mass concentration $\mathrm{c}=\mathbf{8 0} \%$

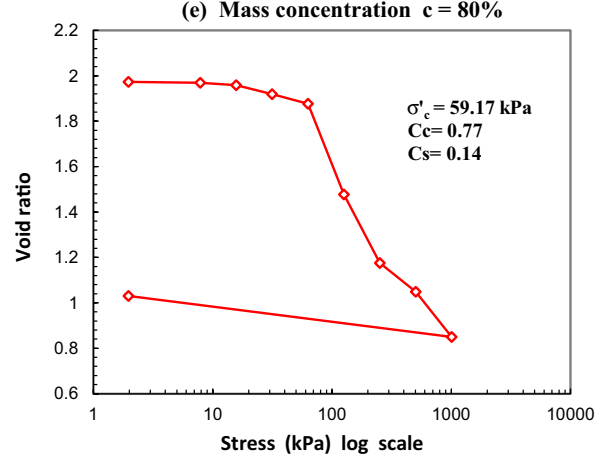

(b) Mass concentration $\mathrm{c}=\mathbf{2 0} \%$

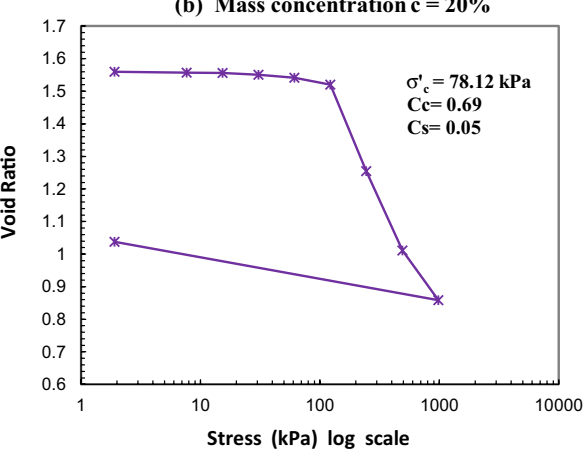

(d) Mass concentration c $=60 \%$

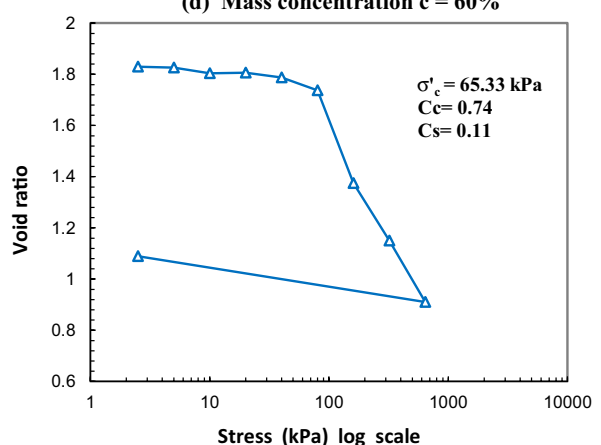

(f) Mass concentration $\mathrm{c}=100 \%$

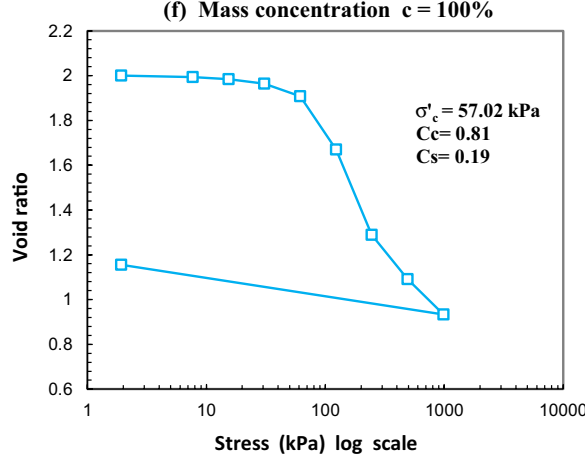

Fig. 7 Void ratio versus effective stress logarithmic scale for clay saturated with: a water only; b-f Benzene at various concentrations, respectively 
Table 4 Compression and swelling indices for clay saturated with water and Benzene at different concentrations

\begin{tabular}{|c|c|c|c|c|c|c|}
\hline & \multirow{2}{*}{$\begin{array}{l}\text { Water only } \\
c=0 \%\end{array}$} & \multicolumn{5}{|c|}{ Benzene mass concentration $\%$} \\
\hline & & $c=20 \%$ & $c=40 \%$ & $c=60 \%$ & $c=80 \%$ & $c=100 \%$ \\
\hline Cc & 0.20 & 0.69 & 0.73 & 0.74 & 0.77 & 0.81 \\
\hline Cs & 0.04 & 0.05 & 0.09 & 0.11 & 0.14 & 0.19 \\
\hline$\sigma_{c}^{\prime}(\mathrm{kPa})$ & 90.70 & 78.12 & 72.65 & 65.33 & 59.17 & 57.02 \\
\hline$e_{0}$ & 0.93 & 1.56 & 1.73 & 1.83 & 1.97 & 2.00 \\
\hline
\end{tabular}

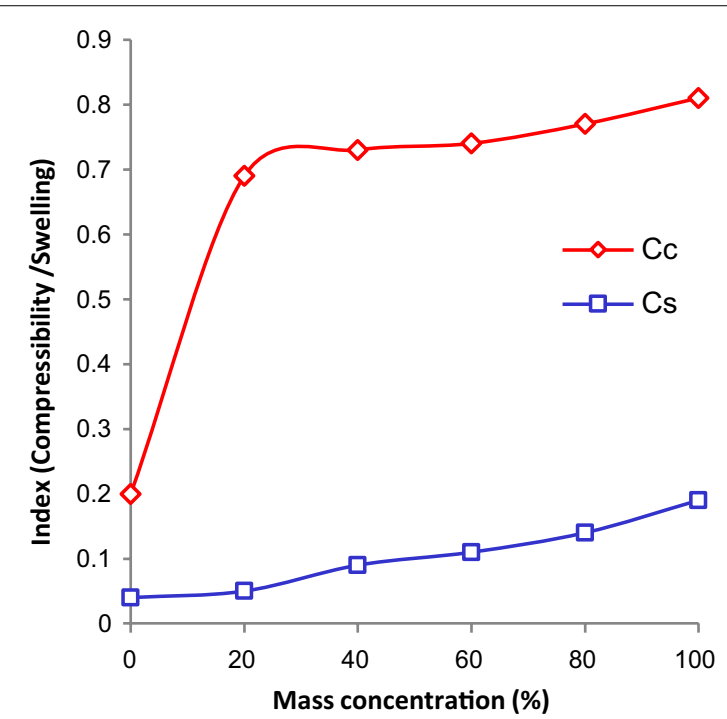

Fig.8 Variation of Compression and swelling indices for clay saturated with water only and Benzene at various concentrations

higher concentration ( $c=60 \%$ to $c=100 \%$ ) makes it higher. It is worth mentioning that a higher mechanical swelling is obtained $(\mathrm{Cs}=0.04$ to $\mathrm{Cs}=0.19)$. In addition, Table 4 shows the compression index $\mathrm{Cc}$ and the swelling index $\mathrm{Cs}$ for clay saturated with water and organic solution at different concentrations.

Figure 8 shows a very rapid increase of the compressibility coefficient Cc of $245 \%$ compared to a relatively small increase of the concentration $(c=20 \%)$. Beyond this value, we observe a relative stabilisation of the increase of the same coefficient of compressibility, we then have values of $17.4 \%$. On the other hand, in terms of the swelling coefficient we observe a linear increase but with a more important amplitude compared to the compressibility coefficient, this increase of the Cs coefficient is $345 \%$ for an increase concentration from 0 to $100 \%$ of benzene.

Inorganique solutions like (Hydrochloric acid and potassium hydroxide) scarcely affect one-dimensional compressibility, whereas sodium hydroxide at low concentrations reduces the compression index [34]. Whereas Organic solutions (Benzene) influenced one-dimensional compressibility. The results indicate a strong increase in compressibility (Cc from 0.20 to 0.81 ) and a significant increase in swelling (Cs from 0.04 to 0.19 ), when the saturation liquid changes from water to benzene (c from 0 to $100 \%$ ). These 
Table 5 Hydraulic conductivity of water and benzene into Constantine clay

\begin{tabular}{llll}
\hline saturation liquid & Water only & Water/benzene & Benzene only \\
\hline $\mathrm{K}(\mathrm{m} / \mathrm{s})$ & $9.92 \times 10^{-8}$ & $7.94 \times 10^{-11}$ & $3.09 \times 10^{-7}$ \\
\hline
\end{tabular}

results are in perfect agreement with Fig. 8. However, the results of the uniaxial compression tests had shown that a water-immiscible benzene could not completely replace the water in the clay matrix of a soil initially saturated with water. The settlement that occurs under a pure hydrocarbon spill area is therefore likely to be much lower than the compressibility values obtained.

The contribution of benzene to swelling cannot be explained by the double layer theory developed by Gouy [35, 36] and Chapman [37]. Indeed, the double layer theory suggests that swelling occurs when the clay particle and the surrounding cations are in an aqueous dispersive medium and, since the composition of the adsorbed cations does not remain constant when the concentration and mineral composition of the aqueous medium varies, ion exchange occurs. The water molecule is neutral overall, but since the oxygen and hydrogen atoms in water are not symmetrically arranged and have electrically opposite charges, water molecules are dipoles that promote magnetic repulsion between minerals with the same eclectic charge. Thus the amplitude of the swelling depends on the type of mineral present in the water. Now, when the soil is saturated with the mixture (water/benzene), a constant volume of area that occupies an inter-particle space in the dry state of the soil is divided into two completely different parts, the first by the water and the second by the benzene which is an immiscible element. This means that the mineral load initially present in a unit area volume occupied entirely by water during saturation is reduced as a function of the increase in the concentration of benzene. This theoretically leads to a decrease in swelling. The results obtained show the opposite effect, i.e. a very significant increase in swelling as a function of the increase in the concentration of the pollutant. This leads us to propose another explanation.

When they fall into the field of action of the electric potential of a clay particle or a cation, the water dipoles are attracted by their surface. This is called hydration of the particles and cations with adsorption of a hydrated shell. The water dipoles directly in contact with the surface of the mineral particle are strongly attracted and are stacked so densely in the first layer (over 20 to 30 rows of molecules) that the water acquires solidlike properties. The formation of this strongly bound water layer is accompanied by a significant energy effect, in the form of heat release, and as benzene is a volatile element this heat causes it to evaporate as a gas. Thus the significant increase in the void index as a function of concentration is attributed to this gas.

\section{During specific oedometric test}

This section does not focus on the effects of organic chemicals on hydraulic conductivity, but on the effect of organic chemicals on the mechanical properties of clays, where solutions of organic compounds with low water solubility, such as hydrocarbons, do not have a significant effect on hydraulic conductivity [11-13]. However, it can be noted that the rate of water leakage is rapid during the first few hours, then decreases and becomes constant, which corresponds to the permanent hydraulic regime. The same seepage 
experiment was carried out with benzene. The hydraulic conductivity in Table 5 shows that clays immersed in an organic solution (benzene) are slightly more impermeable than clays immersed in water, but of the same order of magnitude. Thus, it is important to say that this permeability is very low and has no effect on the mechanical properties of the clay.

The natural clay sample initially saturated with water has a very low permeability to benzene, which is explained by the non-miscibility of these two liquids. Indeed, Mitchell and Madsen [38] observed that organic products that are poorly soluble in water tend to flow into the soil macropores, where they exist; they hardly displace the water present in the clay matrix. On the other hand, a sample of natural clay initially saturated with benzene has a higher benzene permeability than the water permeability of a sample of natural clay initially saturated with water. In this work, after the test, strong cracking of the benzene saturated samples was found. This is consistent with the observations of Anderson et al. [39], who measured the permeability of a Heptane clay in relation to its water permeability. Hydrocarbons induce shrinkage and cracking of the sample, generating macro-porosity and an increase in permeability of several orders of magnitude. Thus, in practice, for a natural clay, if cracking is prevented (significant containment), the permeability decreases significantly with the passage of the hydrocarbon. The progression of the hydrocarbon through the clay layer is considerably slowed down. On the other hand, Mitchell and Madsen [38] reported that permeability is unaffected by most organic products diluted in water (within the limits of their solubility). Finally, in the absence of sufficient containment, the cracking caused by the arrival of pure benzene leads to a strong increase in permeability and therefore compromises the effectiveness of the clay layer.

Table 6 provides a summary of the data, and Fig. 9 shows the most important data for this experiment.

Only two cases are presented with or without the presence of an effective external stress, first in the absence of chemical liquid, i.e., by the presence of pure water only ( $c=0 \%$ ), and then under the effect of the chemical liquid.

In analysing Fig. 9, it should first be noted that in the absence of external stress, the maximum seepage stress $\left(\mathrm{P}_{\max }\right)$ induced by the imposed water flow $(\mathrm{c}=0 \%)$ is high, reaching $112 \mathrm{kPa}$ and giving a significant settlement of $0.45 \mathrm{~mm}$. However, during contaminant flow, settlements were higher for $20-40 \%$ of the mass concentration, even though the seepage forces were higher. These observations suggest that significant swelling deformation occurred during permeation. On the contrary, at $60-80-100 \%$ of the mass concentration, settlements were lower and seepage forces were much lower.

Then, at an externally imposed stress $(160 \mathrm{kPa})$, no such swelling is observed during permeation of the chemical liquid. Instead, visible consolidation occurs during permeation already at $40-80 \%$ of the concentration. It is clear that part of this consolidation can be attributed to increased seepage forces. And at $100 \%$ concentration, observations suggest a slight swelling deformation occurring during permeation.

The chemo-plastic model formulation can be adapted to determine the elastic and plastic strains from the experimental data [24]. A single flux of organic contaminant in the clay is assumed. The intensity of the chemical contamination is quantified by the mass concentration of the chemical, which can be written as follows: 
Table 6 Degree of saturation, effective stress, and settlement for water-compacted samples permeated with water and Benzene

\begin{tabular}{|c|c|c|c|c|c|c|c|}
\hline \multirow[t]{3}{*}{ Banzane (\%) } & \multirow{3}{*}{$\begin{array}{l}\text { Initial degree } \\
\text { of saturation } \\
S_{0}(\%)^{a}\end{array}$} & \multicolumn{3}{|c|}{ Effective stress (kPa) } & \multirow{3}{*}{$\begin{array}{l}\text { Final gradiant } \\
i_{f}\end{array}$} & \multicolumn{2}{|c|}{ Settlement } \\
\hline & & \multirow{2}{*}{$\begin{array}{l}\text { Initial } \\
\sigma_{v 0}^{\prime} \text { (static) }\end{array}$} & \multicolumn{2}{|l|}{ Final $^{b}$} & & \multirow[t]{2}{*}{ Static $^{c}$} & \multirow[t]{2}{*}{ Sepage $^{d}$} \\
\hline & & & $\sigma_{v f}^{\prime}($ static $)$ & $P_{\max }$ (sepage) & & & \\
\hline 0 & 100 & 0 & 0 & 112 & 560 & 0 & 0.452 \\
\hline 10 & 95 & 0 & 0 & 146 & 730 & 0 & 0.401 \\
\hline 20 & 98 & 0 & 0 & 177 & 885 & 0 & 0.215 \\
\hline 40 & 100 & 0 & 0 & 205 & 1025 & 0 & 0.193 \\
\hline 60 & 100 & 0 & 0 & 102 & 510 & 0 & 0.152 \\
\hline 80 & 98 & 0 & 0 & 30 & 150 & 0 & 0.117 \\
\hline 100 & 96 & 0 & 0 & 10 & 50 & 0 & 0.101 \\
\hline 0 & 97 & 40 & 40 & 145 & 725 & 0.08 & 0.321 \\
\hline 40 & 98 & 40 & 40 & 250 & 1250 & 0.116 & 0.425 \\
\hline 80 & 98 & 40 & 40 & 200 & 1000 & 0.132 & 1.063 \\
\hline 100 & 98 & 40 & 40 & 25 & 125 & 0.132 & 0.924 \\
\hline 0 & 97 & 80 & 80 & 179 & 895 & 0.375 & 0.625 \\
\hline 40 & 98 & 80 & 80 & 265 & 1325 & 0.329 & 0.825 \\
\hline 80 & 98 & 80 & 80 & 244 & 1220 & 0.348 & 0.882 \\
\hline 100 & 97 & 80 & 80 & 30 & 150 & 0.346 & 0.973 \\
\hline 100 & 98 & 120 & 120 & 286 & 1430 & 0.476 & 1.194 \\
\hline 0 & 100 & 160 & 160 & 238 & 1190 & 0.449 & 1.491 \\
\hline 40 & 98 & 160 & 160 & 332 & 1660 & 0.473 & 1.597 \\
\hline 80 & 98 & 160 & 160 & 355 & 1775 & 0.502 & 1.652 \\
\hline 100 & 98 & 160 & 160 & 150 & 750 & 0.692 & 1.488 \\
\hline
\end{tabular}

a Initial degree of saturation calculated immediately following compaction and sample trimming to a thickness of $20 \mathrm{~mm}$. Predamage stresses were then applied to the water-wet compacted samples prior to permeation with reference water ( 0.01 $\mathrm{NCaCaSO}_{4}$

${ }^{\mathrm{b}}$ Final effective stresses refer to end of permeation with Benzene-leachate mixtures and reflect relaxation for $\sigma_{v f}^{\prime}$

' $S$ tatic settlement for water-wet samples on application of $\sigma_{v f}^{\prime}$

${ }^{d}$ Seepage settlements are total settlements for initial reference water followed by pure leachate, pure Benzene, or Benzeneleachate mixture

$$
c=\frac{m_{c}}{m_{f}}
$$

where, $(c)$ is the chemical concentration, $m_{c}$ is the mass of the chemical and $m_{f}$ is the total mass of the fluid.

The value of total volumetric straine $\varepsilon_{v}$, can be calculated from the vertical settlements measured directly in the experiment. Total strain can be decomposed into an elastic part and a plastic part. The elastic part can be decomposed into mechanical and chemical contributions. The estimation of the volumetric plastic strain for plastic flow states is based on the principle of additivity for small strains, which reads as follows:

$$
\varepsilon_{v}=\varepsilon_{v}^{e}+\varepsilon_{v}^{P}=\varepsilon_{v}^{m, e}\left(p^{\prime}\right)+\varepsilon_{v}^{c, e}(c)+\varepsilon_{v}^{P}\left(p^{\prime} ; c\right)
$$

The chemical expansion in the elastic part can be obtained by the difference between the total strain (measured experimentally) and the mechanically induced stress-dependent strain, as follows: 


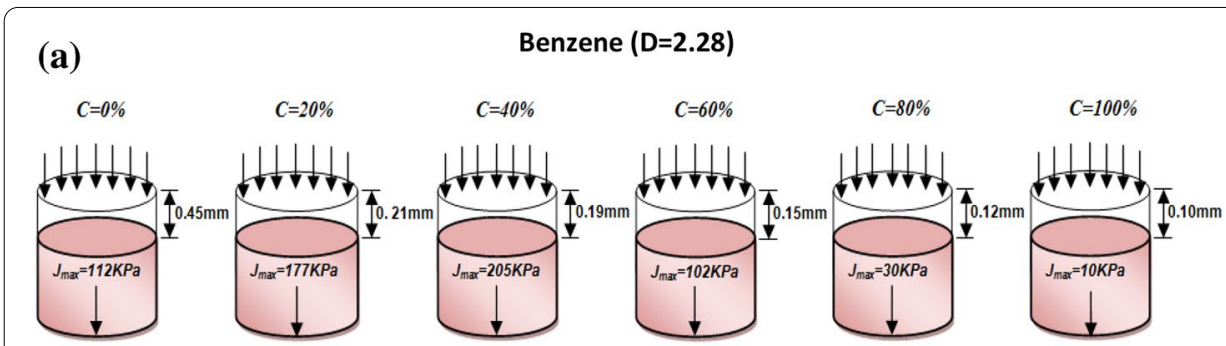

(b)
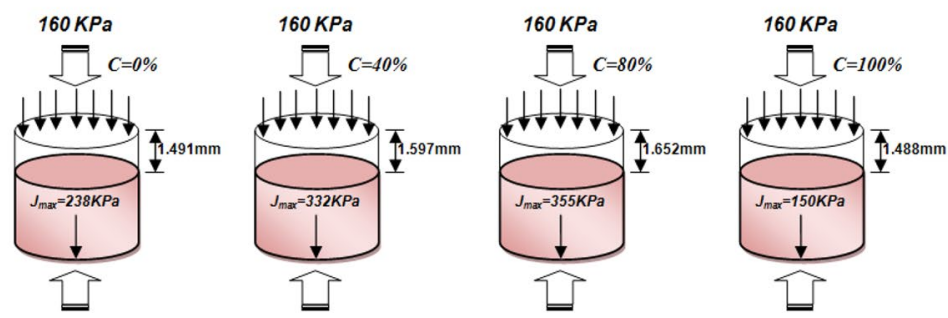

Fig. 9 Pictures showing clay samples under volumetric stress at different external loads versus maximum leakage strength due to flow of gasoline at different concentrations. a No Imposed external effective stress (induced Seepage stress), b Imposed external effective stress (induced external stress)

$$
\varepsilon_{v}^{c, e}(c)=\varepsilon_{v}-\varepsilon_{v}^{e}\left(p^{\prime}\right)
$$

where, the mechanically induced volumetric strain is:

$$
\varepsilon_{v}^{e}\left(p^{\prime}\right)=\frac{\kappa}{1+e_{0}} \ln \frac{p^{\prime}}{p_{0}^{\prime}}
$$

The volumetric plastic strain is defined by the associated flow rule as follows:

$$
\varepsilon_{v}^{P}\left(p^{\prime} ; c\right)=\varepsilon_{v}-\varepsilon_{v}^{e}\left(p^{\prime}\right)-\varepsilon_{v}^{c, e}(c)
$$

Figure 10 shows the values measured in experiments and model predictions of the total volumetric strain at different external loads relative to the benzene concentrations in the reference clay.

The total volumetric strain resembles settlement due to initial static consolidation under load in water only, followed by settlement due to the flow of water and thus chemical liquid. Table 6 gives the settlement values. Figure 10(a-d) show that the measured total effective stresses increase steadily and monotonically with concentration to an optimal value close to $40-60 \%$, followed by a rapid decrease to well below the initial values (for $\mathrm{c}=100 \%$ ). The differences between the measured stresses and thus the mechanically induced stresses are considered in this model as those of chemical expansion.

In addition, Fig. 10(e-h) illustrates a component of the volumetric deformation that can result from purely mechanical loads in the absence of any chemical effect. These purely mechanical loads include the vertical stress applied externally and also the strain within the specimen induced by the built-in seepage forces. An average is taken 

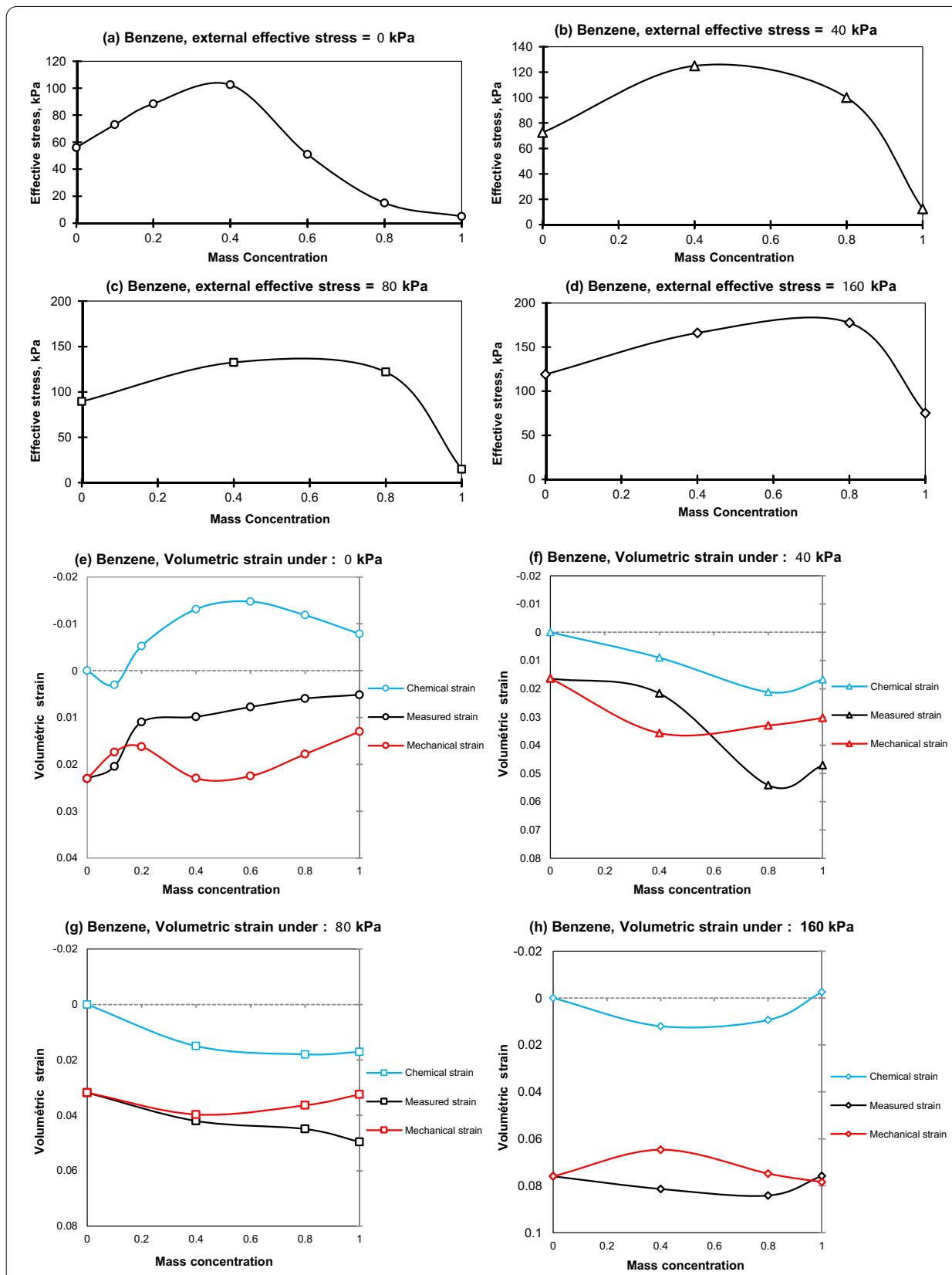

Fig. 10 Experimental data and model predictions for the volumetric response of benzene impregnated Constantine clay under an external overload of 0-160 kPa: a-d effective vertical stress as a function of concentration, $\mathbf{e}-\mathbf{h}$ volumetric strain as a function of concentration

for the appropriate seepage stress $\left(\mathrm{P}_{\max } / 2\right)$. It should be noted that the strain at certain states was calculated by including the loading and unloading history in an elastic state, when the total stress during contaminant flow was only that imposed during water flow. The difference between the measured stress and the mechanically induced stress is due to chemical effects.

For uncompressed samples, the measured strain at the lowest bit concentration may be a smaller amount than that which occurs during water flow, and also the strain due to 
mechanical loading. The chemically induced strain is therefore expansive in all respect concentrations, and increases with concentration up to about $60 \%$. However, for concentrations above $80 \%$, the difference in strain appears to be compressive. For pre-compressed samples, the (measured) strain curves are very different, especially at $\mathrm{c}=80$ and $100 \%$, so the chemically induced strain is different from that of samples that were not pre-compressed. Therefore, the chemical strain is compressive, and at $\mathrm{c}=100 \%$ becomes smaller than at $\mathrm{c}=0 \%$. It should be noted that total strains (measured) in uncompressed benzene impregnated samples are expansive at low concentrations. Then, for pre-compressed samples at intermediate concentrations, the clay appears more consolidated, and finally, at high concentrations, it becomes less consolidated again.

When impregnating the clay with benzene after the flow of pure water without external stress, such a state (chemo-elastic strain) can occur at low concentrations, due to the increase in average seepage stresses. A standard is taken for the capable seepage stress $\left(\mathrm{P}_{\max } / 2\right)$, from 56 to $73 \mathrm{kPa}$ and $83.5 \mathrm{kPa}$, at concentrations of 10 and $20 \%$ respectively, resulting in a low effective stress relief, as shown in Fig. 10a-d. The measured strain rate associated with this void is expanding, but is expected to result from elastic discharge, resulting in a decrease in the total compressive strain, as shown in Fig. 10a. We assume that chemical softening up to $\mathrm{c}=20 \%$ does not yet visibly affect the elasticity surface. However, at $c=40 \%$ the leakage pressures increase due to the change in viscosity of the permeability, resulting in a slight yield, and we will therefore only consider the elastic states at $\mathrm{c}=40 \%$. It is therefore assumed that pure elastic chemical strain occurs at $\mathrm{c}=40 \%$. After a slight increase in the effective stress at $\mathrm{c}=40 \%$, the strain drop starts. Despite the stress produced by the leakage and thus at the effective pressure, the swelling of the specimen is stopped. The presence of a compression strain difference at concentrations above approximately $\mathrm{C}=60 \%$, despite the effective stress unloading, led us to assume that chemo-plastic consolidation occurred. Furthermore, at concentrations between $(\mathrm{c}=80 \%$ and $\mathrm{c}=100 \%$, there is no significant change in effective stress, and therefore no change in expected mechanical stress, and there is no significant change in measured total strain. This suggests that at concentrations between $C=80 \%$ and $C=100 \%$, there is no additional chemo-plastic consolidation, to be attributed to an effective visit stress faster than chemical softening, causing an unloading. It also suggests that at concentrations between ( $c=80 \%$ and $\mathrm{c}=100 \%$ ) there is no further chemo-elastic expansive strain.

Chemo-mechanical softening curve of Constantine clay/benzene Figure 11 shows the analysis results obtained by HPLC on clay samples polluted by benzene. A certain fluctuation in the contamination rate is observed during the tests (for $24 \mathrm{~h}$ ). This fluctuation reflects the effect of saturation of the sediment by the contamination, followed by a leaching effect. It can also be deduced that the hysteresis phenomenon between the quantity absorbed and the quantity remaining in solution highlights the existence of the reversible reaction between absorption and desorption.

The sensitivity is evaluated quantitatively to determine the chemical softening function $S(c)$. Thus, an exponential chemical softening rule that is insensitive to the load is interpolated between all available points obtained experimentally by HPLC analysis on soil samples taken after the chemo-mechanical consolidation tests. The chemical 


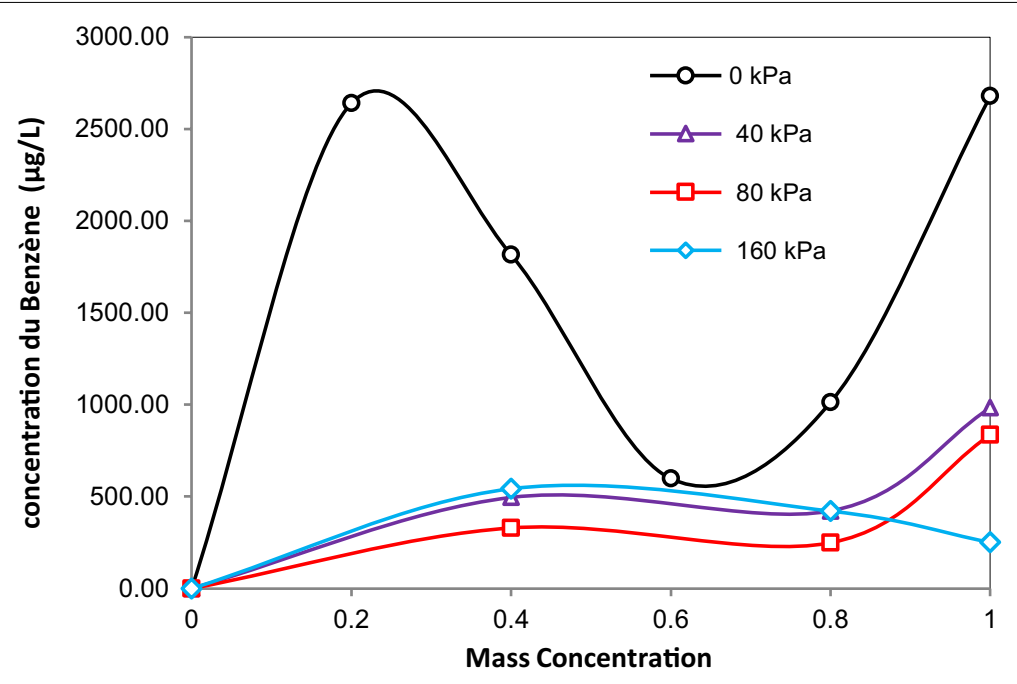

Fig. 11 Variation in the concentration of benzene absorbed and the mass concentration of the mixture injected into Constantine clay under several external overloads

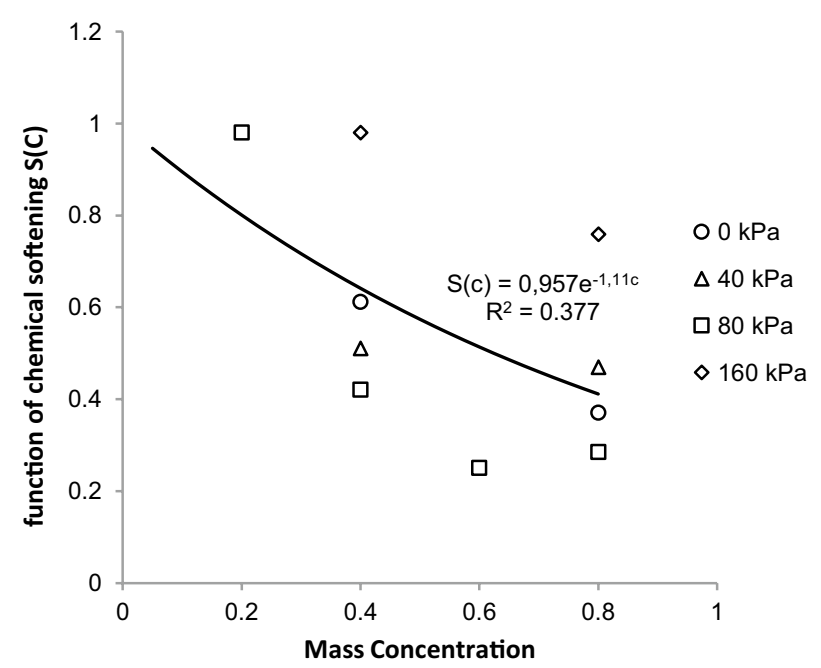

Fig. 12 Chemical softening function $S(c)$ of benzene impregnated Constantine clay

softening function (Eq. 8) is therefore proposed by Hueckel [24] as a simple exponential rule:

$$
S(c)=\exp (-\mathrm{ac})
$$

where, $(a)$ is the chemical softening exponent and $(c)$ is the mass concentration.

Figure 12 shows the trend curve linking the mass concentration and chemical softening of benzene-impregnated soils; this curve has the same general shape as that proposed by Hueckel [24] on the basis of experimental data on Sarnia clay 
impregnated with an organic mono-contaminant (ethanol and dioxane) reported by Fernandez and Quigley [2]. There is, however, one remarkable difference, such as the appearance of a new parameter (called A in this study). This purely experimental parameter depends both on the chemical nature of the contaminant and the environment through which it passes. This leads to a new formulation of Eq. (8) as follows:

$$
S(c)=\mathbf{A} \cdot \exp (-\mathrm{ac})
$$

Figure 13 shows the different trains of the chemo-mechanical softening function of different clays contaminated with several types of organic solutions, which differs slightly from the values for ethanol and dioxane obtained by Hueckel [24]. It therefore appears that the chemical softening exponent of benzene $(\mathrm{a}=1.11)$ is lower than that of dioxane $(\mathrm{a}=2.78)$ and ethanol $(\mathrm{a}=3.45)$. This low value for the chemical softening exponent of benzene is due to its low solubility in water. In addition, the value of benzene parameter $(A=0.957)$, defined according to Eq. (8), differs slightly from the values obtained by Hueckel [24] for ethanol and dioxane $(A=1)$. The coefficients of determinations $\left(R^{2}\right)$ are low, which implies a weak correlation of the data with the trend curves proposed for: benzene $\left(R^{2}=0.377\right)$, dioxane $\left(R^{2}=0.233\right)$ and ethanol $\left(R^{2}=0.395\right)$. This situation is due to the dispersion of the values of the results of the chemical analysis obtained for a constant concentration. The dispersion is probably due to the large range of values of the imposed loads (0-40-80-160) $\mathrm{kPa}$ assigned to each concentration. To remedy this situation, it is necessary to repeat the same chemical analysis protocol but with a large number of samples, that is to say to reduce the difference in the interval between the loads imposed and the chemical concentration.

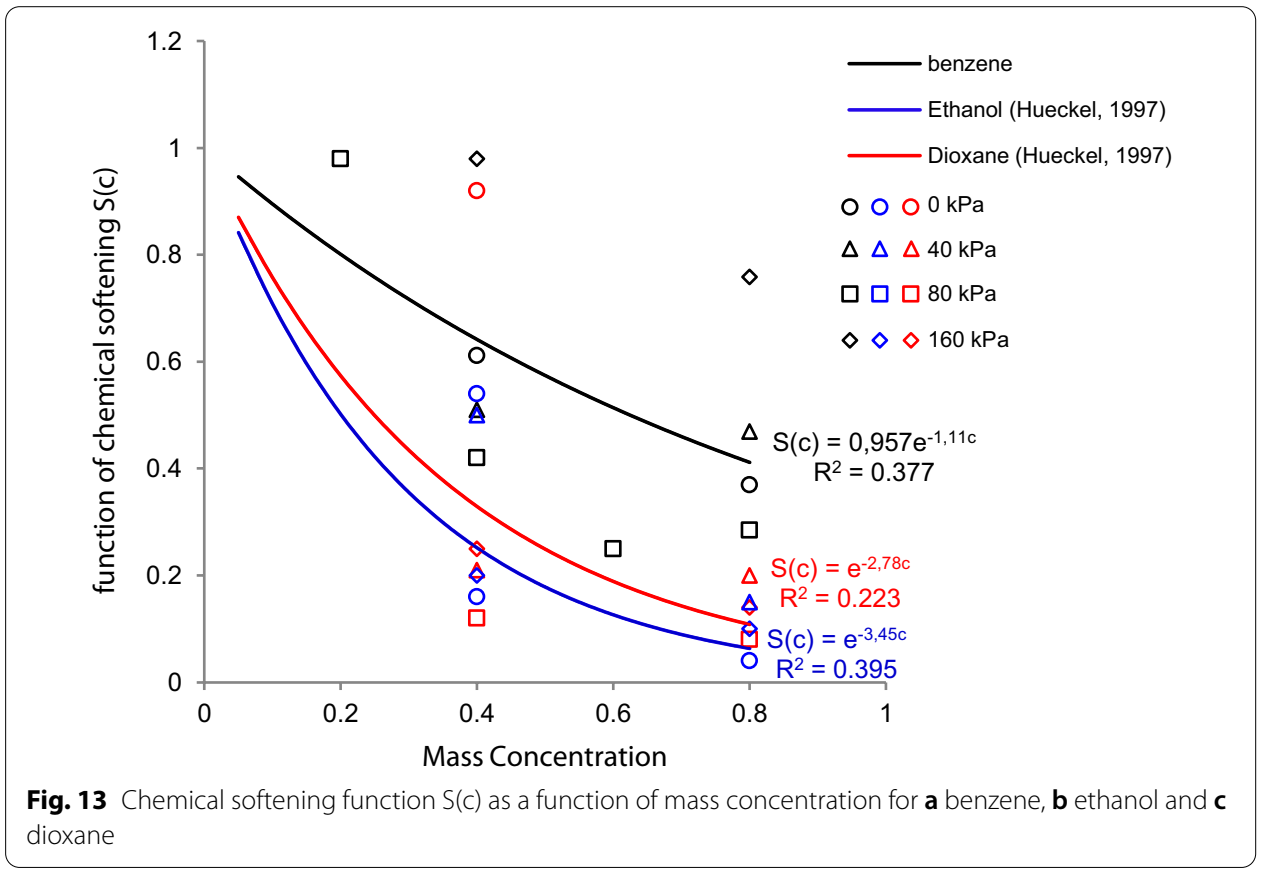




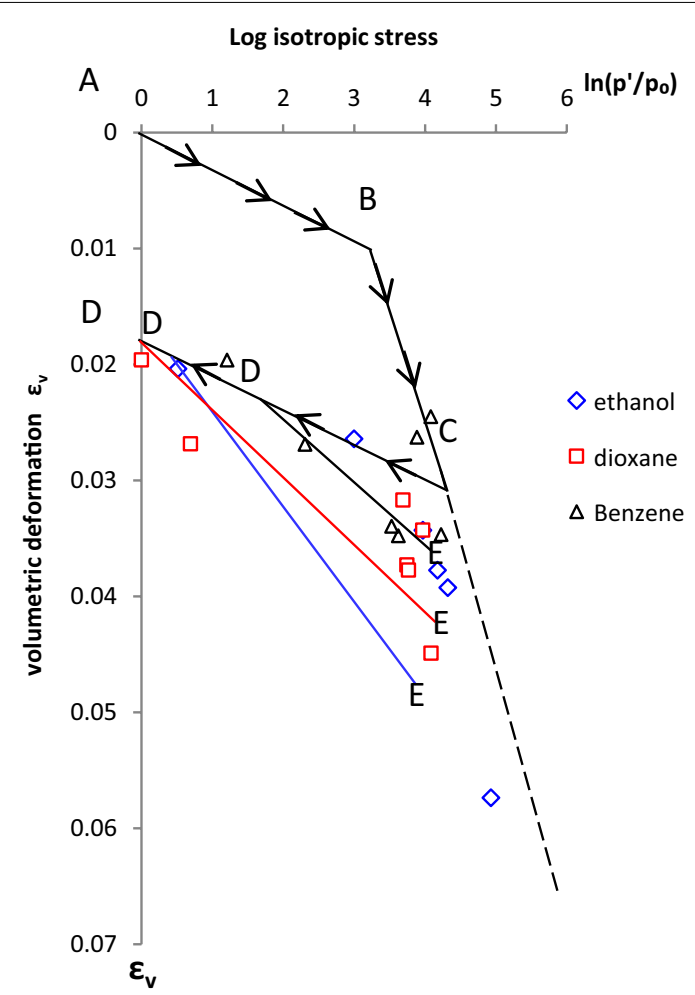

Fig. 14 Experimental results of Log isotropic stress as a function of volumetric deformation in 1-D compression for benzene impregnated Constantine clay compared to ethanol and dioxane impregnated Sarnia clay [24]; ABC is the load due to seepage forces during water flow, C-D is the discharge due to the drop in seepage force and chemo-plastic consolidation and D-E is the plastic load of the clay impregnated with chemical contaminant

Furthermore, Fig. 14 shows loading paths in the Log isotropic stress $\ln \left(p^{\prime} / p_{0}\right)$ as a function of volumetric deformation $\varepsilon_{v}$ in 1-D compression. carried out on samples of Constantine clay impregnated with benzene, compared to the results of Sarnia clay impregnated with ethanol and dioxane [2]. The $A B C$ path represents the load due to infiltration forces during the flow of water only $(\mathrm{c}=0 \%)$. The $\mathrm{CD}$ path is a discharge due to the decrease in the infiltration force and to the chemoplastic consolidation, in fact according to Eq. (7) we have a decrease in the value $\varepsilon_{v}$, with a reduction in the quantity $\varepsilon_{v}^{e}$ in Eq. (6) and a chemo-elastic strain $\varepsilon_{v}^{c, e}(c)=0$. The trend paths D-E representing the plastic loading of clays impregnated with pure chemical contaminant $(c=100 \%)$, were obtained, using the experimental results of Table 6.

Thus, during post-damage loading (DE) on Sarnia clay, it is easy to see that the slope of the line DE of ethanol (2.37\%) was almost twice as strong as that of dioxane (1.48\%). For Constantine clay impregnated with benzene this slope is of the order of $1.63 \%$, close to the effect of dioxane, so the effect of the insoluble pollutant benzene on clays has a reliable influence on the deformability than the soluble contaminant. 

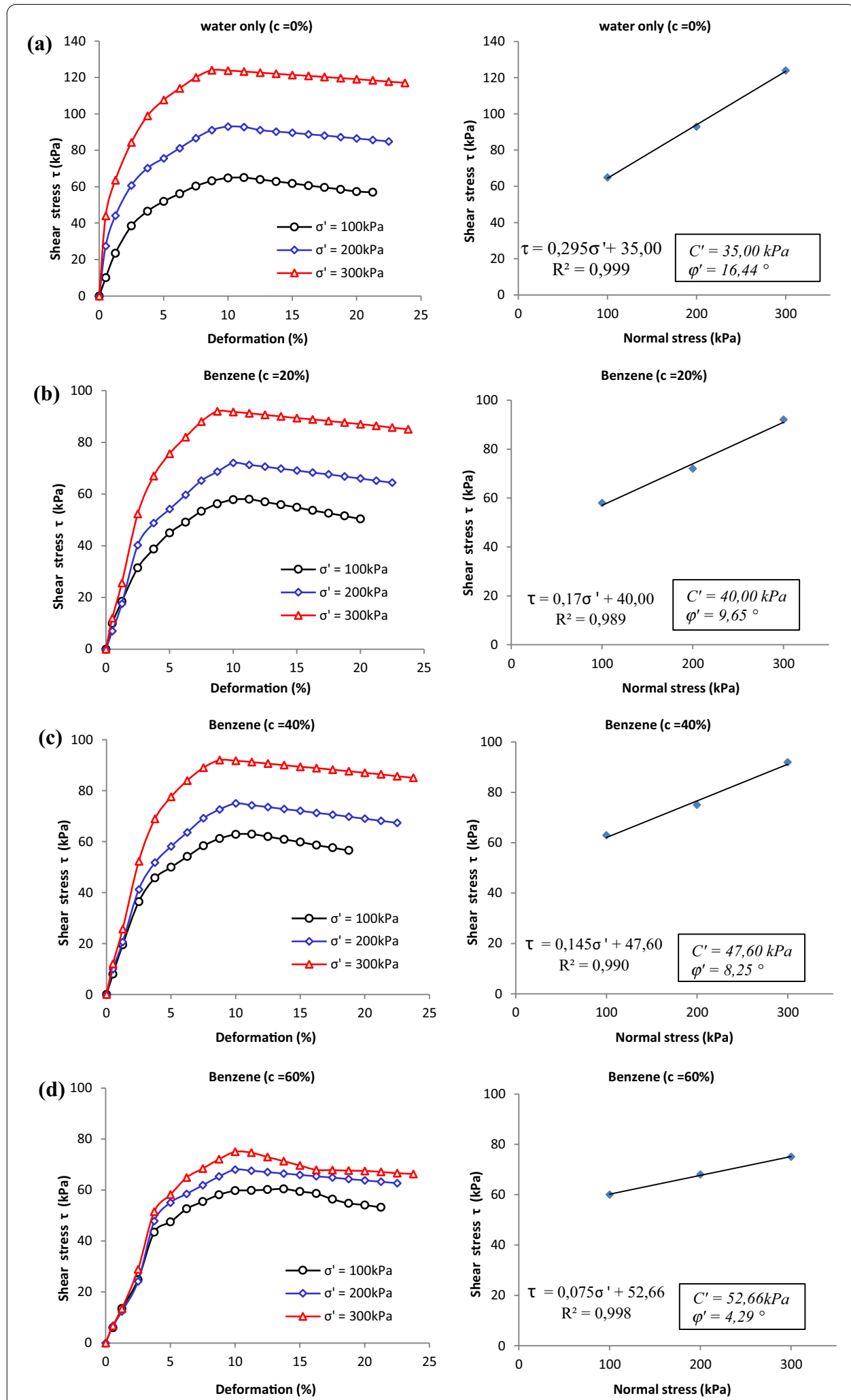

Fig. 15 Horizontal displacement curve and Mohr-Coulomb model of rupture for clay saturated with: a water only; a-f Benzene at various concentrations, respectively 


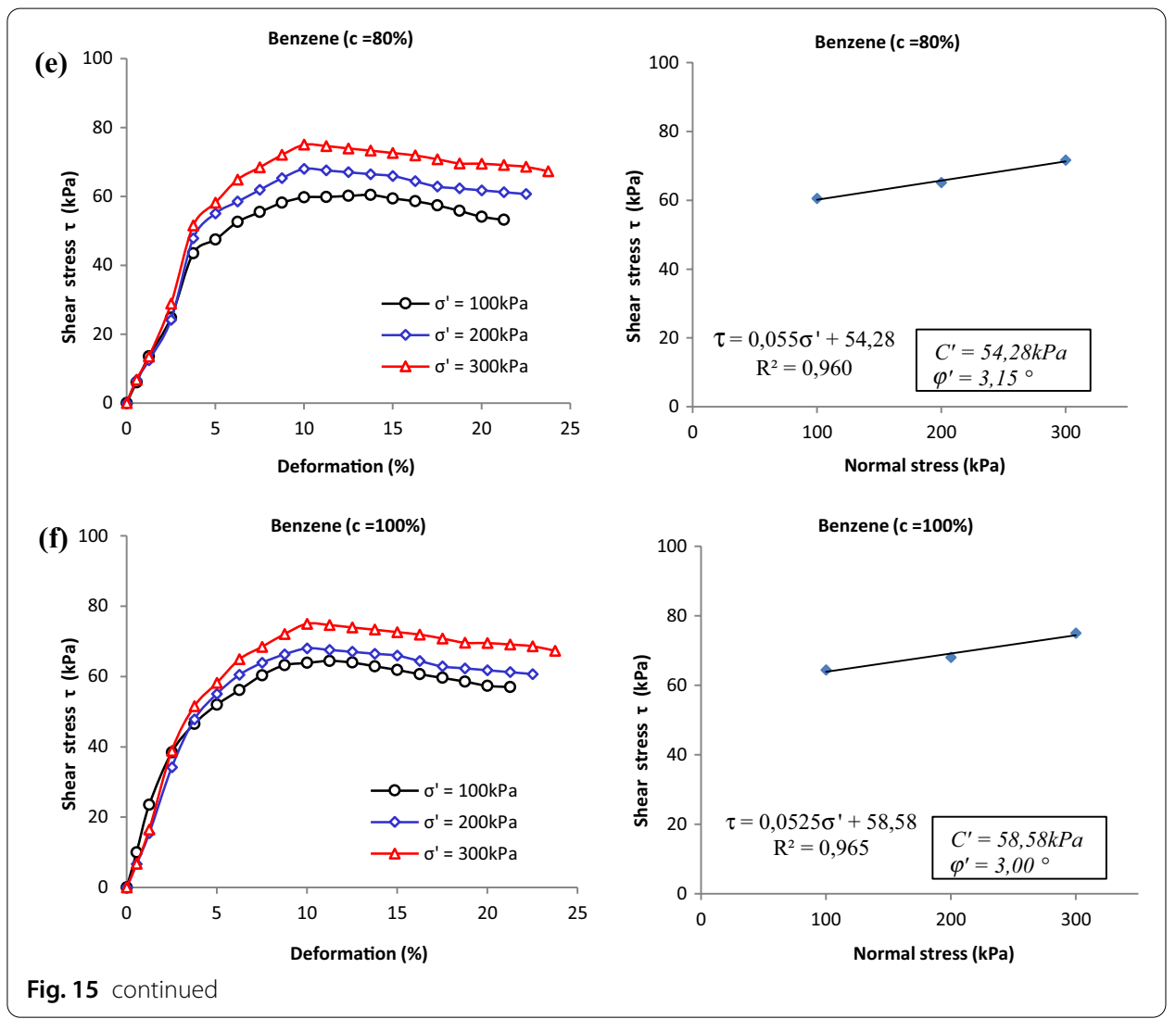

Table 7 Variation of cohesion and friction angle as a function for clay samples saturated with water only or Benzene at different concentrations

\begin{tabular}{|c|c|c|c|c|c|c|}
\hline & Water Only & Benzene & s concentr & $n \%$ & & \\
\hline & $c=0 \%$ & $c=20 \%$ & $c=40 \%$ & $c=60 \%$ & $c=80 \%$ & $c=100 \%$ \\
\hline $\begin{array}{l}\text { Cohesion } \\
\mathrm{C}^{\prime}(\mathrm{kPa})\end{array}$ & 35.00 & 40.00 & 47.60 & 52.66 & 54.28 & 58.58 \\
\hline $\begin{array}{l}\text { Friction angle } \\
\varphi^{\prime}\left(^{\circ}\right)\end{array}$ & 16.44 & 9.65 & 8.25 & 4.29 & 3.15 & 3.00 \\
\hline
\end{tabular}

\section{During shear strength test}

The shear test was carried out on samples of natural clay saturated with distilled water and benzene solution at different concentrations to assess the degree of irreversibility of the chemical effects on the mechanical behaviour of the samples. Figure 15 illustrates the evolution of the shear strength of the clay in relation to the horizontal displacement under the three normal stresses applied. Figure 15a-f shows that the shear strength of the samples previously saturated with water only and a solution of benzene at various concentrations suggested a certain degree of reversibility of the chemo-mechanical effects; i.e., the increase in the friction angle induced by the initial samples saturated with distilled water only is partially cancelled out (significant decrease) by subsequent inundation with a benzene solution at various concentrations. 


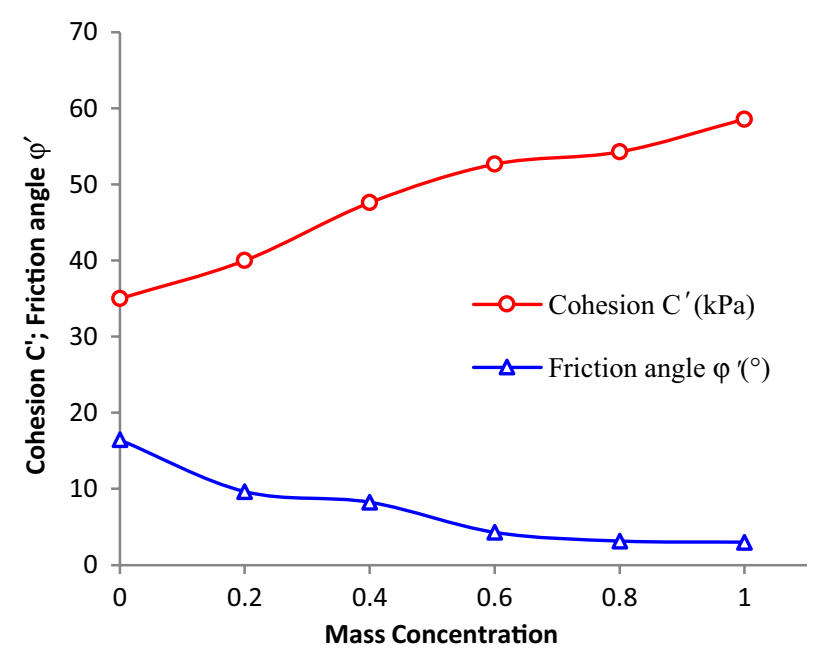

Fig. 16 Evolution of cohesion and angle of friction angle, for clay samples saturated with water only or Benzene at various concentrations

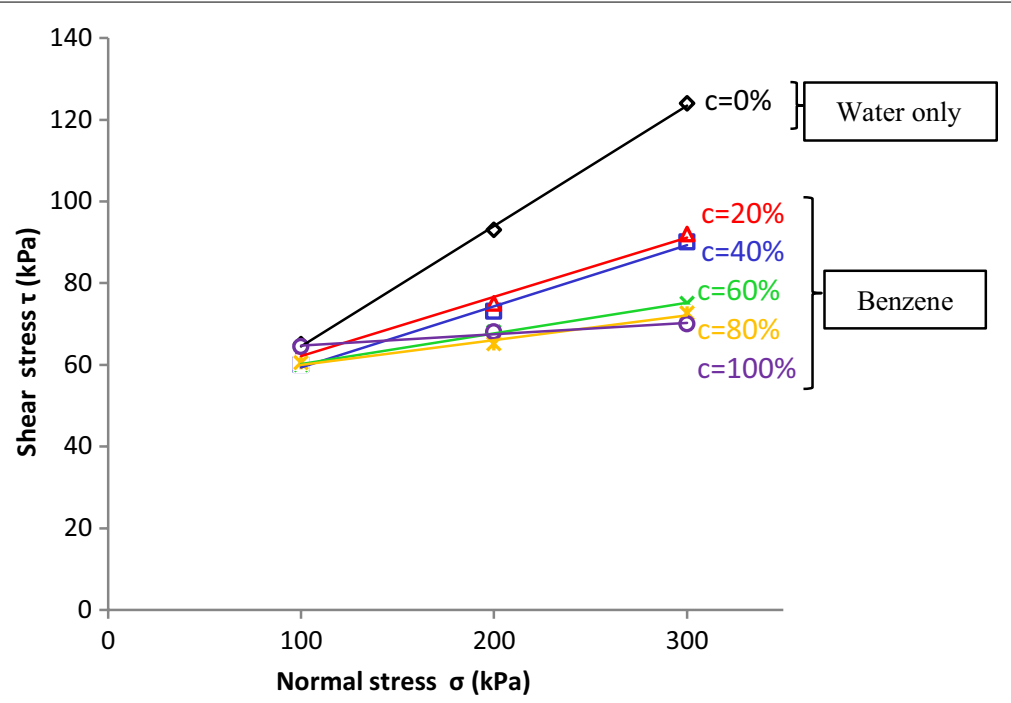

Fig. 17 Failure stresses for clay samples saturated with water only or Benzene at various concentrations

The results listed in Table 7 show the variation in cohesion and angle of friction of soil saturated with water only or benzene solution, indicating a strong increase in cohesion ( $C^{\prime}$ from 35 to $58.58 \mathrm{kPa}$ ) and, conversely, a significant decrease in the friction angle $\left(\phi^{\prime}\right.$ from $16.44^{\circ}$ to $\left.3^{\circ}\right)$.

This decrease is partially offset by an increase in cohesion (Fig. 16). It is also important to note that the variations in cohesion and angle of friction as a function of the soil matrix saturated with organic chemicals are non-linear.

Figure 16, shows the effect of benzene on the variation of the mechanical characteristics of the soil, the angle of internet friction and the cohesion. We observe that the cohesion increased significantly from an initial value of $36.18 \mathrm{kPa}$ (value corresponding to a water saturation only) to a final value of $58.58 \mathrm{kPa}$ (value corresponding to a 
pure benzene saturation) with an increase rate of about $62 \%$. On the other hand, the same concentrations of benzene gave us an exponential decrease of the angle of internal friction, we have a rate of decrease of the order of $81.7 \%$.

Figure 17 shows the fracture stresses in the Mohr plane for Constantine clay impregnated with water or benzene solution at different concentrations. The direct shear tests give results very comparable to those of the compression tests interpreted by the usual method and to those of the compression test results interpreted taking into account the inclination of the fracture planes. In fact, the straight lines which delimit the pin contain the representative points of the shear tests in the plane $\left(\sigma^{\prime}, \tau\right)$, (Fig. 16) are defined respectively by the parameters $\left(C^{\prime}, \phi^{\prime}\right)$ in the samples contaminated at different concentrations. As the samples subjected to the direct shear test were sheared in horizontal planes a priori unaffected by clay cracking, the measured strength is that of the clay matrix, which confirms the conclusions of the analysis of the compression test results.

The effect of the increase of the concentration of benzene causes a change of behaviour in the form of flattening of the lines of critical states. Therefore and as an example for an initial configuration i.e. before contamination, if we have a stress state represented by a point of coordinate $\sigma=200 \mathrm{kPa}, \tau=80 \mathrm{kPa}$ in the reference frame $\sigma$ : normal stress and $\mathrm{r}$ : tangential stress (see Fig. 17), this state is said to be elastic. Now, if we take the same point but with respect to a different concentration $(c \neq 0)$, we observe that the corresponding soil stress state is in the failure state. Therefore we can conclude that the same soil and under the effect of benzene contamination becomes less elastic.

The experimental conditions chosen (consolidated and drained test type) indicate a decrease in the friction angle and an increase in cohesion. Poor control of the drainage conditions may be at the origin of the observed results. Indeed, it can be assumed that the training of cracking zones in the vicinity of the imposed shear plane accelerates the drainage during the test. The complexity of the phenomena involved would require the performance of tests where the experimental conditions are better controlled (as in the case of a triaxial apparatus). On the other hand, the influence of the nature of the saturation liquid on the mechanical properties of the clay soils studied shows the preponderance of interactions of a physico-chemical nature between the interstitial fluid and the clay particles in this type of soil. However, from a qualitative point of view, we observe a significant increase in the mechanical characteristics of clay soils saturated in benzene solution compared to the same soils saturated with water.

In practice, it seems that a massive influx of benzene solution into a tested soil mass does not represent a threat to its stability. However, it can be noted that a soil totally saturated in benzene solution was a borderline case never observed in practice, because a water-immiscible hydrocarbon cannot totally replace the water in the clay matrix of the soil. It is likely that the mechanical strength of the soil will be little affected by the presence of an organic chemical.

Chemo-mechanical interactions and volume changes in clay are controlled mainly by shear strength at close contact points, as volume changes occur mainly as a result of sliding between particles [40,41]. Some sort of correlation could therefore exist between residual shear strength and compression index, but this is not the case. Indeed, a lower angle of friction for an organic solution is associated with a decrease in the compression 
index instead of the expected increase, while a higher angle of friction induced by benzene seepage coincides with negligible changes in the compression index. One possible explanation for this inconsistency is that changes in kaolinite volume could be at least partially related to the slippage of the edge-to-edge contact points.

\section{Conclusion}

Experimental analyses were carried out on samples of natural clay, saturated with distilled water and benzene solution at different concentrations. The results show that the mechanical behaviour of intact natural clay is strongly influenced by organic chemicals. The following conclusions can be drawn from the experimental study:

1. The hydraulic properties are slightly influenced by organic chemicals. These effects are slightly correlated with water solubility, dielectric constant, polarity and whether the soil is exposed to pure organic solution or diluted solution. This is consistent with the general belief that the interactions between clay particles are primarily mechanical.

2. Organic solutions (benzene) influence the one-dimensional compressibility, when the saturation liquid changes from water to benzene ( $c=0$ to $100 \%$ ), the results indicate a strong increase in compressibility $(\mathrm{Cc}=0.20$ to 0.81$)$ and a significant increase in swelling ( $\mathrm{Cs}=0.04$ to 0.19$)$. However, the results of the oedometer tests had shown that a water-immiscible benzene could not totally replace the water in the clay matrix of a soil initially saturated with water. The settlement that occurs under a pure hydrocarbon spill area is therefore likely to be much greater than the original values of compressibility ( $c=0 \%)$.

3. The presence of effective vertical stresses on the consolidated clay in the presence of water prior to benzene permeation, results in uniformity in the plugging of large pores and shrinkage cracks caused by the initial decompression of the samples. As a result, this clogging leads to an increase in hydraulic conductivity. Contamination under relatively modest external compressive overload produced low plastic compressive strain and virtually stable permeability. In the case of medium vertical stress, there was a decrease in compressibility and an increase in incorporation rates in samples subjected to high concentration flow, when applied pressures were low and initial void rates high.

4. All results confirm the influence of the pollutant at different concentrations on the mechanical behaviour of the soil and also contribute to a significant increase in cohesion. The soil becomes compressible and swells simultaneously; more cohesive and less frictional; less elastic. In addition, the intact natural clay samples have friction angles that vary significantly with the variation in concentration; i.e. the friction angle is smaller with high concentrations and higher with low concentrations. The organic liquid (benzene) plays an important role in this process. These effects are also partially reversible, so they are probably related to a change in basal surface properties mainly due to chemical-base reactions on the surface sites.

5. Chemo-mechanical interactions and volume changes in clay are primarily controlled by the shear strength at close contact points, as changes in volume occur mainly due to sliding between particles. A sort of correlation therefore exists between the shear 
strength and the compression index. Indeed, a lower friction angle induced by the infiltration of benzene is associated with an increase in the compression index, while a higher friction angle coincides with significant changes in the compression index. A possible explanation for this consistency is that volume changes in clay could be related to the sliding of the contact planes between particles.

\section{Acknowledgements}

The author wishes to thank Dr. Gheris Abderrahimb and Profesor Guenfoud Mohameda for contributed to the study conception and design. Material preparationand for elaborating the results.

\section{Authors' contribution}

HK carried out the studies and the discussion of the physico-mechanical and chimical tests and specific oedometric tests and participated in the drafting of the manuscript. AG performed the interpretation of the results of the petrographic and chemical characterization (HPLC) and participated in the drafting of the manuscript. MG participated in the design of the experimental protocol and in the drafting of the manuscript. All authors read and approved the final manuscript.

\section{Declarations}

Competing interests

The authors declare that they have no competing interests.

\section{Author details}

${ }^{1}$ Civil Engineering and Hydraulics Laboratory, 8 Mai 1945 University, Guelma, Algeria. ${ }^{2}$ InfraRES Laboratory, Mohammed Cherif Messaadia University, Souk Ahras, Algeria.

Received: 1 August 2020 Accepted: 24 May 2021

Published online: 20 October 2021

\section{References}

1. Madsen FT, Mitchell JK (1989) Chemical effects on clay fabrics and hydraulic conductivity. The landfill. Springer, Berlin, pp 201-251

2. Fernandez F, Quigley RM (1991) Controlling the destructive effects of clay-organic liquid interactions, by application of effective stresses. Can Geotech J 28(3):388-398

3. Nalbantoglu Z, Tuncer ER (2001) Compressibility and hydraulic conductivity of a chemically treated expansive clay. Can Geotech J 38(1):154-160

4. Mitchell JK, Soga K (2005) Fundamentals of soil behaviour, vol 3. John Wiley \& Sons, New York

5. Gens A (2010) Soil-environment interactions in geotechnical engineering. Géotechnique 60(1):3-74

6. DeJong JT, Soga K, Kavazanjian E, Burns S, Van Paassen LA, Al Qabany A et al (2014) Biogeochemical processes and geotechnical applications: progress, opportunities and challenges. In: Bio-and chemo-mechanical processes in geotechnical engineering: géotechnique symposium in print 2013. Ice Publishing. p. 143-157.

7. Ganzenmüller GC, Hiermaier S, May M (2015) On the similarity of meshless discretizations of peridynamics and smooth-particle hydrodynamics. Comput Struct 150:71-78

8. Di Maio C (1996) Exposure of bentonite to salt solution: osmotic and mechanical effects. Geotechnique 46(4):695-707

9. Barbour SL, Yang N (1993) A review of the influence of clay-brine interactions on the geotechnical properties of Ca-montmorillonitic clayey soils from western Canada. Can Geotech J 30(6):920-934

10. Abdul AS, Gibson TL, Rai DN (1990) Laboratory studies of the flow of some organic solvents and their aqueous solutions through bentonite and kaolin clays. Groundwater 28(4):524-533

11. Fernandez F, Quigley RM (1985) Hydraulic conductivity of natural clays permeated with simple liquid hydrocarbons. Can Geotech J 22(2):205-214

12. Delage P, Alzoghbi-Massaad P, Jun Cui Y (2000) Air, water and oil transfers in an unsaturated compacted silt. Proceedings of the international symposium on physical modelling and testing in environmental geotechnics, LaBaule, pp. 61-68

13. Cui YJ, Delage P, Alzoghbi P (2003) Retention and transport of a hydrocarbon in a silt. Géotechnique 53(1):83-91

14. Castellanos E, Villar MV, Romero E, Lloret A, Gens A (2008) Chemical impact on the hydro-mechanical behaviour of high-density FEBEX bentonite. Physics and chemistry of the earth, parts A/B/C, 33, S516-26

15. Alonso EE, Gens A, Josa A (1990) A constitutive model for partially saturated soils. Géotechnique 40(3):405-430

16. Loret B, Khalili N (2002) An effective stress elastic-plastic model for unsaturated porous media. Mech Mater 34(2):97-116

17. Loret B, Hueckel T, Gajo A (2002) Chemo-mechanical coupling in saturated porous media: elastic-plastic behaviour of homoionic expansive clays. Int J Solids Struct 39(10):2773-2806

18. Moyne C, Murad MA (2002) Electro-chemo-mechanical couplings in swelling clays derived from a micro/macrohomogenization procedure. Int J Solids Struct 39(25):6159-6190

19. Boukpeti N, Charlier R, Hueckel T (2004) Modelling contamination of clays. Elsevier geo-engineering book series, vol 2. Elsevier, Hoboken, pp 523-528 
20. Guimarães LDN, Gens A, Olivella S (2007) Coupled thermo-hydro-mechanical and chemical analysis of expansive clay subjected to heating and hydration. Transp Porous Media 66(3):341-372

21. Detournay E, Sarout J, Tan C, Caurel J (2005) Chemoporoelastic parameter identification of a reactive shale. In: IUTAM symposium on physicochemical and electromechanical interactions in porous media. Springer, Dordrecht, pp 125-132

22. Bunger AP (2010) The Mandel-Cryer effect in chemoporoelasticity. Int J Numer Anal Meth Geomech 34(14):1479-1511

23. Sarout J, Detournay E (2011) Chemoporoelastic analysis and experimental validation of the pore pressure transmission test for reactive shales. Int J Rock Mech Min Sci 48(5):759-772

24. Hueckel T (1997) Chemo-plasticity of clays subjected to stress and flow of a single contaminant. Int I Numer Anal Meth Geomech 21(1):43-72

25. Hueckel T (2005) Chemo-mechanics of geomaterials: coupled constitutive laws. Revue européenne de génie civil 9(5-6):689-711

26. Bui TA (2014) Etude théorique et numérique du comportement poro-plastique endommageable non saturé des géomatériaux: application au stockage de déchets radioactifs (Doctoral dissertation, École Nationale des Travaux Publics de l'État [ENTPE])

27. Bourenane H, Guettouche MS, Bouhadad Y, Braham M (2016) Landslide hazard mapping in the Constantine city, Northeast Algeria using frequency ratio, weighting factor, logistic regression, weights of evidence, and analytical hierarchy process methods. Arab J Geosci 9(2):154

28. ASTM Standard (2019) Standard Test Methods for Soils. Conshohocken, ASTM, p 19428

29. Terzaghi K, Peck RB (1957) Stabilization of an ore pile by drainage. J Soil Mech Found Div 83(1):1144-1151

30. Qlihaa A, Dhimni S, Melrhaka F, Hajiaji N, Srhiri A (2016) Caractérisation physico-chimique d'une argile Marocaine [Physico-chemical characterization of a morrocan clay]. J Mater Environ Sci 7(5):1741-1750

31. Perez-Carvajal J, Aranda P, Ruiz-Hitzky E (2019) Titanosilicate-sepiolite hybrid nanoarchitectures for hydrogen technologies applications. J Solid State Chem 270:287-294

32. Crawford BR, Faulkner DR, Rutter EH (2008) Strength, porosity, and permeability development during hydrostatic and shear loading of synthetic quartz-clay fault gouge. J Geophys Res Solid Earth. https://doi.org/10.1029/2006J B004634

33. Konan KL, Soro J, Andji JY, Oyetola S, Kra G (2010) Etude comparative de la déshydroxylation/amorphisation dans deux kaolins de cristallinité différente. J de la Société Ouest-Africaine de Chimie 30:29-39

34. Wahid AS, Gajo A, Di Maggio R (2011) Chemo-mechanical effects in kaolinite. Part 1: prepared samples. Géotechnique 61(6):439-447

35. Gouy G (1910) Sur la constitution de la charge électrique à la surface d'un électrolyte. Journal Phys. 9(1):457-468

36. Gouy G (1917) Sur la fonction électrocapillaire. Ann. Phys. (Paris) 9(7):129-184

37. Chapman DL (1913) A contribution to the theory of electrocapillarity. The London, Edinburgh, and Dublin Philosophical Magazine and Journal of Science. 25(148):475-481

38. Mitchell JK, Madsen FT (1987) Chemical effects on clay hydraulic conductivity. In: Geotechnical practice for waste disposal'87. ASCE, pp 87-116

39. Anderson DC, Brown KW, Thomas JC (1985) Conductivity of compacted clay soils to water and organic liquids. Waste Manage Res 3(4):339-349

40. Sridharan A, Rao GV (1973) Mechanisms controlling volume change of saturated clays and the role of the effective stress concept. Geotechnique 23(3):359-382

41. Sridharan A, Venkatappa Rao G (1979) Shear strength behaviour of saturated clays and the role of the effective stress concept. Geotechnique 29(2):177-193

\section{Publisher's Note}

Springer Nature remains neutral with regard to jurisdictional claims in published maps and institutional affiliations.

\section{Submit your manuscript to a SpringerOpen ${ }^{\circ}$ journal and benefit from:}

- Convenient online submission

- Rigorous peer review

- Open access: articles freely available online

- High visibility within the field

Retaining the copyright to your article

Submit your next manuscript at $\gg$ springeropen.com 